University of Louisville

ThinkIR: The University of Louisville's Institutional Repository

Electronic Theses and Dissertations

$5-2017$

\title{
The lose-lose situation : identity prioritization and gendered communication in co-recreational intramural basketball.
}

Megan Robinson

University of Louisville

Follow this and additional works at: https://ir.library.louisville.edu/etd

Part of the Gender and Sexuality Commons, and the Sports Studies Commons

\section{Recommended Citation}

Robinson, Megan, "The lose-lose situation : identity prioritization and gendered communication in corecreational intramural basketball." (2017). Electronic Theses and Dissertations. Paper 2727. https://doi.org/10.18297/etd/2727

This Master's Thesis is brought to you for free and open access by ThinkIR: The University of Louisville's Institutional Repository. It has been accepted for inclusion in Electronic Theses and Dissertations by an authorized administrator of ThinkIR: The University of Louisville's Institutional Repository. This title appears here courtesy of the author, who has retained all other copyrights. For more information, please contact thinkir@louisville.edu. 


\title{
THE LOSE-LOSE SITUATION: \\ IDENTITY PRIORITIZATION AND GENDERED COMMUNICATION IN CO-RECREATIONAL INTRAMURAL BASKETBALL
}

\author{
By \\ Megan Robinson \\ B.A., Hanover College, 2015 \\ A Thesis \\ Submitted to the Faculty of the \\ in Partial Fulfillment of the Requirements \\ For the Degree of \\ Masters of Arts \\ in Sociology \\ Department of Sociology \\ University of Louisville \\ Louisville, Kentucky
}

College of Arts and Sciences of the University of Louisville

May 2017 
Copyright 2017 by Megan Robinson

All Rights Reserved 



\title{
THE LOSE-LOSE SITUATION: IDENTITY PRIORITIZATION AND GENDERED COMMUNICATION IN CO-RECREATIONAL INTRAMURAL BASKETBALL
}

\author{
By \\ Megan Robinson \\ B.A., Hanover College, 2015
}

A Thesis Approved on

March 29, 2017

By the following Thesis Committee:

Thesis Director

Dr. Mark Austin

Dr. Patricia Gagne

Dr. Mary Ashlock 


\section{DEDICATION}

This thesis is dedicated to my parents

Mr. Roland Robinson

and

Mrs. Melissa Robinson

who have helped guide me to be the woman I am today. 


\section{ACKNOWLEDGEMENTS}

I would like to thank my Thesis Committee Chair, Dr. Mark Austin, for his

willingness to work with me. Thank you to the rest of my committee, Dr. Patricia Gagne and Dr. Mary Ashlock. The guidance provided by my entire committee helped me in creating something of which I am truly proud. I would also like to thank Steven Russ and Aubrey Woolley. The two of you have given me an ear, a shoulder, and endless support. Thank you all. 


\section{ABSTRACT \\ THE LOSE-LOSE SUTATION: \\ IDENTITY PRIORITIZATION AND GENDERED COMMUNICATION \\ IN CO-RECREATIONAL INTRAMURAL BASKETBALL \\ Megan Robinson}

March 29th 2017

Co-recreational sports deserve to be studied due to their relationship between the environment, identity prioritization, and gendered communication for individuals. In spite of the environment's importance in collegiate student development, few have asked the questions of: how do co-recreational intramural basketball players manage their multiple identities and statuses when playing with or against members of the same or opposite sex; and how do players of both sexes use gendered communication strategies to negotiate predominantly masculine leisure environments, like intramural basketball leagues? Using in-depth interviews from co-recreational intramural basketball players at the University of Louisville triangulated with observations of corecreational intramural basketball games, results are uncovered to show that players manage their multiple statuses in ways that differ by gender and skill level and claim to negotiate the predominantly masculine leisure environment if they feel they should, though they rarely do. 


\section{TABLE OF CONTENTS}

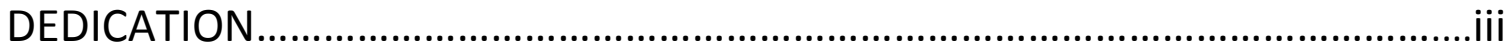

ACKNOWLEDGEMENTS..................................................................................

ABSTRACT

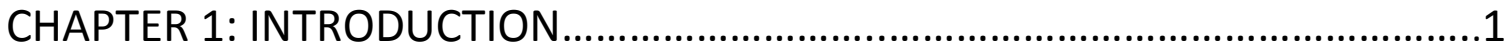

Research Questions...........................................................................................

Potential Implications............................................................................................

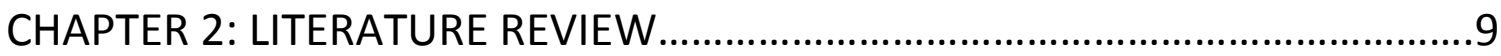

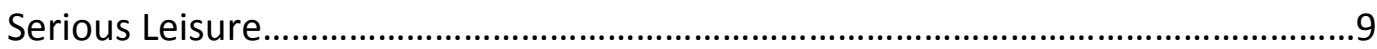

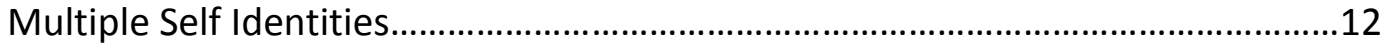

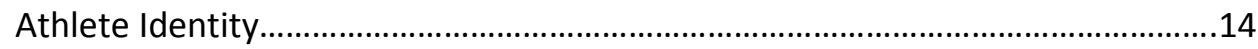

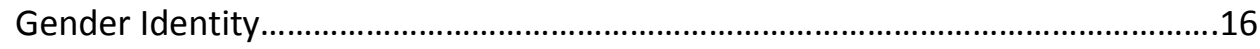

Gendered Communication....................................................................................21

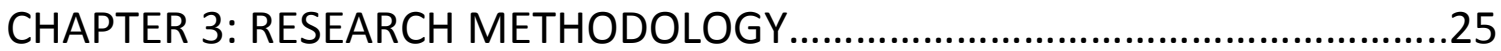

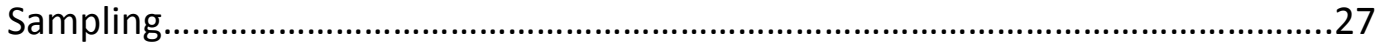

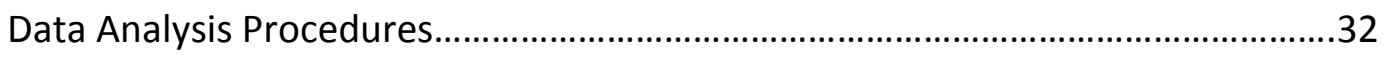

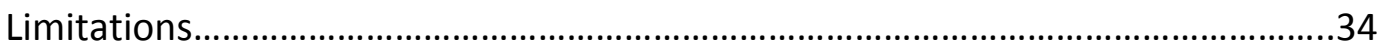

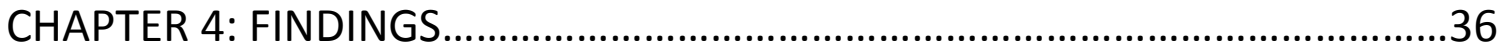

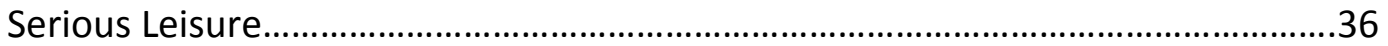

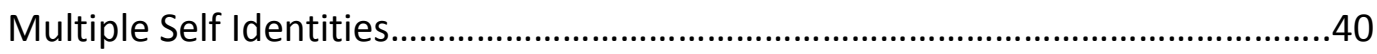

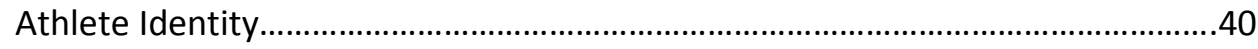

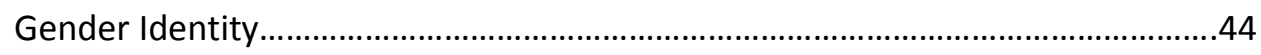

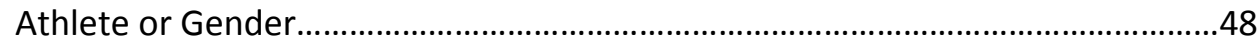

Gendered Communication..................................................................................50 
Guarding a Man or a Woman.

Man or Woman Teammate Hitting a Three Point Shot..........................................53

Man or Woman Teammate Turning the Ball Over..................................................55

Man or Woman Teammate Getting Injured........................................................57

Negotiating a Predominantly Masculine Environment..........................................58

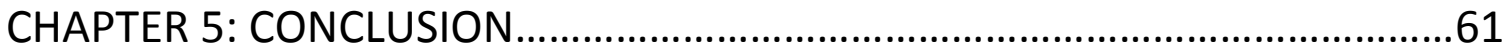

The Lose-Lose Situation in a Serious Leisure Situation.........................................63

Explaining Choices Regarding Athlete and Gender Identities................................65

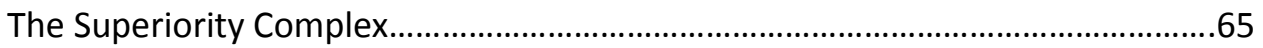

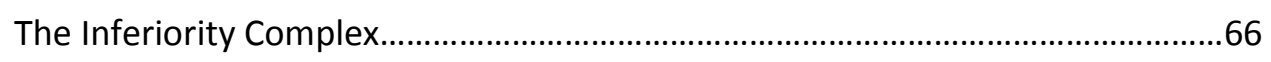

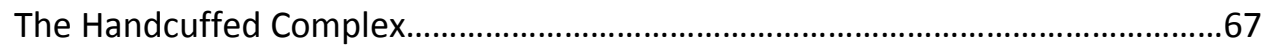

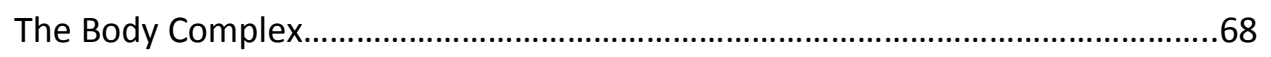

Explaining Gendered Communication Styles....................................................69

Larger Implications for Research and Society......................................................70

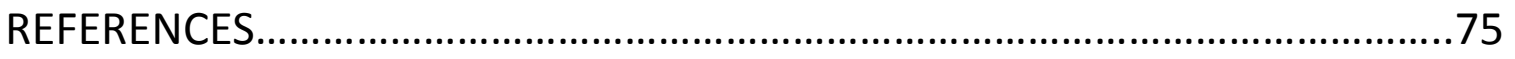

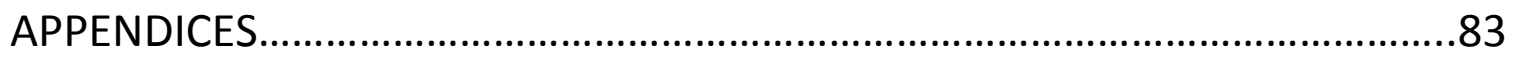

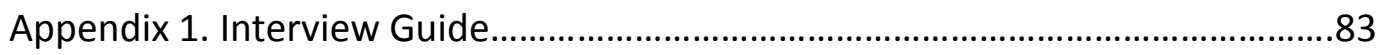

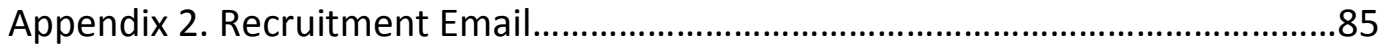

Appendix 3. Informed Consent Form .................................................................. 86

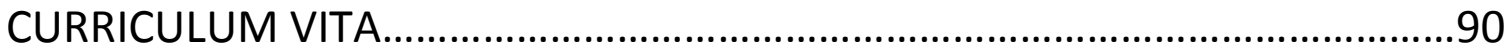




\section{CHAPTER 1: INTRODUCTION}

Colleges and universities encourage participation in co-curricular activities, those linked to what is being taught academically, and some extracurricular activities, those affiliated with the school system but not directly connected to the curriculum (Kuh, Schuh, and Whitt 1991; "University Rewards... Co-curricular Events” 2004; Tenhouse 2008; Great Schools Partnership 2013). A particular extracurricular activity being promoted, however, is what is of interest in this study: intramural sports. This extracurricular activity falls under the umbrella of recreational sport and more broadly, under leisure, or activity that is freely participated in because is it enjoyable and the participant feels confident in their abilities in that activity (Stebbins 2005; NIRSA 2015). Given the placement of intramural sport in leisure studies (Bocarro, Kanters, and Casper 2006; Stevenson, Lochbaum, and Lowe 2007), history of positive effects on personal identity creation/maintenance (Chen, Snyder, and Magner 2010), relation to identity prioritization for university students often at key developmental ages (Gibbons and Ashdown 2006), and source of gendered communication strategies (Chand 2005), leisure, and specifically collegiate co-recreational sport, will serve as the major context of the study.

Recreational sports are activities where individuals play just to be active, have fun, and be social (World of Sports Science 2016). Additionally, these sports activities 
are a source of positive outcomes for well-being, as well as a breeding ground for friendly competition (Hamilton 2016). Although benignly competitive, recreational sports are often inclusionary by skill; that, however, is not a typical characteristic of sports in America. Instead, sports are thought to be exclusive given the intense competitive ethic and the win at all costs mentality with which it is associated. Through this range of competitive ethic is where recreational sports, and thus intramural sports, connect those of leisure sport and those of corporate sport, or upper level sport that is often connected with sponsorships and profitability (Clapp 2016). On the sociology of leisure to sociology of sport continuum, where exclusivity, competition, skill, high stakes/rewards, formal rules, and organizational bodies increase as one nears the corporate sport end (NCAA 2016), recreational sport falls in the middle where those of varied commitment levels are invited to participate in a more hedonic, or fun, environment.

Collegiate intramural sport started at Princeton University when in 1857, those representing the freshmen and sophomore classes started playing baseball games against one another for fun (Hyatt 1977; Milton 2008). Given the way in which intramurals began, they were clearly started out of student interest to fill their need for sport and game before intercollegiate sport officially began and were student run until universities took over in 1915 (Stewart 1973; Milton 2008). The transition in leadership signified the unexpectedly thriving leisure activity that was intramural sport. The benefits students received from intramural sports did not change once the universities took reign (and have yet to change according to contemporary research). Students still 
benefitted from fun, sociability, friendly competition, and increased well-being, enabling the university to start advocating for intramurals as a way to enhance the quality of life for students and to institutionally benefit in terms of higher recruitment and retention rates (Artinger, Clapham, Hunt, Meigs, Milord, Sampson, and Forrester 2006; Milton 2008).

Collegiate intramurals for men were the most popular until Title IX, or the prohibition of "gender discrimination in federally funded educational settings", moved to encourage the inclusion of women, which led to an influx of women participants in women's intramural leagues in 1972 that has been growing ever since (Fields 2007, 521). It is not surprising that single-sex intramurals were most prominent given the socialization of boys and girls in elementary and secondary school: boys and girls grew up being taught that boys and girls needed separate recreational sports leagues because they had different needs and abilities and received different benefits when it came to recreational sports (Riemer and Feltz 1997). Additionally, in previous studies, both on high school (although less pertinent to this study) and college athletes, research has found that men may be in a lose-lose situation when faced with an opponent of the opposite sex, as is shown by Carton (1999) from her research on men wrestlers who are faced with the dilemma of wrestling against women: "If he beats her, he beats a girl. And if she beats him, how will he face his friends?" (A1). Even though the competitive ethic may not be as prominent in recreational sports as noted here about high school wrestling, this dilemma may still appear in leisure based environments whether physical or virtual, like intramural basketball or online gaming, for some participants (Bertozzi 
2008). Given this dilemma that many men athletes may face, it is not surprising that many men prefer to play in same-sex leagues over co-recreational ones, even though there are opportunities to play in leagues of both kinds at many colleges and universities.

Young men and women may not be the only ones placing emphasis on single-sex intramural leagues as many colleges and universities report only single-sex participation rates (two of seventy-four division one universities provided co-recreational intramural participation statistics) (Deaner, Geary, Puts, Ham, Kruger, Fles, Wineguard, and Gradis 2012). The university that this study will use as its focus, the University of Louisville, participated in Deaner et. al's (2012) study, noted above and further discussed below, that focused on intramural participation rates. This university was not alone in their focus on same-sex leagues as most other schools only provided all-men or all-women participation statistics (Deaner et. al 2012). Demand is growing, as shown below, for corecreational intramural sports, and specifically that of co-recreational intramural basketball. Regardless, given that many studies on intramural sport also focus on singlesex leagues, it appears that participants and institutions are not the only ones setting co-recreational intramural sports aside.

Due to a lack of research on co-recreational intramurals, there is a clear need for exploration in environments where collegiate men and women come together and interact, especially when the sport itself is viewed as predominantly masculine or feminine. By studying collegiate co-recreational intramural basketball, this study will fill 
the void that is present in university discussions and leisure literature on co-recreational sports participation.

Filling the void on co-recreational intramural sports and its relation to participants' multiple identities is important, but this context is suitable for filling other purposes as well. Another benefit of intramurals for students, noted before and after the change in administration of the recreational activity as well as in contemporary research, is identity creation/maintenance (Jun, Kyle, Grafe, and Manning 2015). As will be discussed, identities formed or maintained by intramural activity are often dynamic, and therefore are situationally prioritized by intramural participants. This identity creation/maintenance and prioritization is a key interest of this study. Therefore, the arena of co-recreational intramural basketball on a college campus is a suitable environment for the study of fluid, personal identity prioritization, or the listing and ranking of personal identities (athlete, gender, etc.) that intramural participants consider salient in the leisure environment that shapes participants' ranking by drawing them into co-recreational interactions.

After addressing the interest of identity, another piece of the co-recreational intramural basketball environment needs addressed: that of gendered communication. In an assessment on Sullivan's (2004) attempt to study intramural environments, Chand (2005) noted that these leisure atmospheres "offer environments rich in nonverbal communication, close camaraderie, and same-sex groups, all factors likely to produce gender-based differences if they exist" (499). First, this provides another reason as to why this context is ideal for a study of this type. Chand (2005) argues that intramural 
environments are strong in nonverbal, as well as verbal, communication, or gestures and/or words exchanged between players on the court regardless of the content of the exchange. In order to find similarities or differences in communication by gender, these are excellent environments in which to explore. Secondly, another part of Chand's (2005) statement gives reason for this study: because Sullivan (2004) promotes research to be done on intramural sports for their richness in same-sex environments, it is not surprising that many researchers (and universities) have overlooked co-recreational leagues by avoiding studying them and reporting participation rates for them. Given the increasing participation in these leagues, as shown above with the rise in co-recreational intramural sport, and specifically basketball, participation, it is important to start discussing them now, while they are still in their infancy of study.

It is imperative to study co-recreational intramural leagues to see if gendered verbal and nonverbal, including symbolic, differences proposed by Wood (2013), discussed below, exist in these leisure environments and help or hinder negotiation of the predominantly masculine context that is co-recreational intramural basketball. Similarly, while there were no differences in Sullivan's (2004) study of gendered communication in soccer and volleyball, the researcher acknowledges that this may have been so because of the leagues chosen for that study. Sullivan (2004) suggests that research must be done in more masculine sports than those of soccer or volleyball, which is exactly what this study proposes to do (Hardin 2009). Studying gendered communication differences in the predominantly masculine environment of basketball (Hanson and Kraus 1999; Birrell 2000; Stephens 2004; Chand 2005; Grubb and Billiot 
2010; Walker and Sartore-Baldwin 2013) may help address the lack of gendered communication differences of Sullivan's (2004) study.

Overall, intramural sports are encouraged activities on many college campuses. There is a strong history behind these experiences and with that history comes a plethora of benefits. Despite the relevance of intramural sport to many college students, other students, colleges and universities, and researchers are overlooking the intramural environment if co-recreational. With the overlooking of co-recreational intramural atmospheres comes a lack of understanding identity prioritization and gendered communication in those settings. Thus, due to the current void in acknowledgement, accessibility of studying identity prioritization, and possible breeding of gendered communication in the stated context of collegiate co-recreational intramural basketball, the following research questions will guide this study:

R1. How do co-recreational intramural basketball players manage their multiple identities and statuses when playing with or against members of the same or opposite sex?

R2. How do players of both sexes use gendered communication strategies to negotiate predominantly masculine leisure environments, like intramural basketball leagues?

\section{POTENTIAL IMPLICATIONS}

Overall, the findings of this study will prove informative for other students and student affairs/involvement programs on college campuses as it will illustrate why participants are choosing co-recreational leagues and how they interact within them. Additionally, this topic deserves to be studied given the contribution it will make to the 
current literature on recreational sport, and intramural sports in particular, by filling the gap that is present on co-recreational leagues' participation. This study will also add to the literature on the interplay between identities and a predominantly masculine leisure environment. Furthermore, the findings may contribute to the greater academic understanding of gendered communication strategies by reinforcing the lack of gendered differences in communication found by Sullivan (2004) or arguing that gendered communication strategies do exist; either option will contribute to theory revolving around communication strategies of men and women. 


\section{CHAPTER 2: LITERATURE REVIEW}

\section{SERIOUS LEISURE}

Having reviewed intramural sport's placement on the sociology to leisure to sociology of sport continuum, it is important to explore what kind of leisure intramural basketball, in particular, may be to participants. Depending on their choice of classification, the participant may or may not find themselves making more or less of a commitment to the activity. In this study, there are likely to be participants who do both. This calls for a review of both serious and casual leisure (Stebbins 2001, 2005, 2008, 2010).

According to Stebbins (2001), serious leisure is defined as:

"...the steady pursuit of an amateur, hobbyist, or career volunteer activity that captivates its participants with its complexity and many challenges. It is profound, longlasting, and invariably based on substantial skill, knowledge, or experience, if not on a combination of these three" (54).

In other words, serious leisure is what one calls an activity about which they are passionately dedicated to mastering regardless of the obstacles that appear while on the journey. There are many leisure activities of which individuals can call serious leisure: gardening, painting, cooking, and even perhaps intramural basketball; it all depends on the individual and his or her leisure preferences. In addition to the 
definition above and the inferences made from it that follow, Stebbins (2010) lists other aspects of a leisure participant engaging in a serious leisure pursuit: fulfilling a leisure career, receiving durable benefits, partaking in a unique social world, and forming a strong identity with the leisure activity.

The aspect that may appear most relevant to expound upon is that of durable benefits or rewards. Participants who adhere to the qualities that classify recreational basketball to be that of serious leisure are likely to mention a variety of personal and social rewards ranging from development of the self (e.g. self-expression, selfgratification, and re-creation of the self) to the enhancement of group experiences (e.g. social attraction, group accomplishment, and maintenance of the group) (Stebbins 2010). While there are benefits and rewards for those who orient themselves casually to recreational basketball, the advantages of serious leisure are likely more tightly linked, as mentioned, to identity creation/maintenance and thus prioritization (Jun et. al 2015).

While many participants are likely to consider co-recreational intramural basketball serious leisure, there may be some who consider it a more casual leisure activity. Instead of engaging in a leisure career like those who claim intramural basketball a serious endeavor, those who play intramural basketball in a casual manner are more likely to consider the activity to be fun and lighthearted (Stebbins 2008). Their serious leisure teammates are more likely to get involved emotionally and physically in a game while they are more likely to maintain a laid-back and carefree attitude. The benefits of causal leisure activities include intrinsic rewards and short-lived 
entertainment (Stebbins 2008). Again, while the benefits of casual leisure are not as numerous or tightly linked to this study's research questions, they are still advantageous over activities which are not considered serious or casual.

As stated, many participants are likely to consider basketball a leisure activity, but given that each player may vary on his or her level of serious or casual leisure classification, each participant is also likely to differ with regard to their level of experience and degree of commitment with this activity. Recreation specialization theory (RST) is an aid to be used in determining how "specialized" an intramural participant may be in regard to recreational basketball. This relates to the serious to casual (or casual to serious to match the direction of the RST levels) leisure spectrum in that as the levels of specialization increase in RST, the level of leisure seriousness increases as well.

There are four stages in the original conceptualization of RST: occasional, generalist, technique specialist, and technique-setting specialist (Bryan 1977). Although the theory was constructed with regard to trout fishing, it may be applied to a broad array of leisure activities (Wellman, Roggenbuck, and Smith 1982; McIntyre and Pigram 1992). At each stage in the continuum of specialization, therefore, it can be said that intramural basketball participants will likely show different levels of specialized knowledge, skill, and centrality (and thus inclinations toward regarding the activity as one of serious leisure) toward the recreational sport; this supports follow-up research to Bryan's (1977) conceptualization of RST. Contemporary research into RST finds that rather than set stages of specialization, perhaps there are set personal qualities, 
behavioral (showing familiarity/specialized knowledge), cognitive (showing skill), and affective (showing centrality), that participants display as they become more specialized (Bricker and Kerstetter 2000; Scott and Shafer 2001; McFarlane 2004). Nonetheless, regardless of a player's position on the specialization continuum or stated type of leisure, one is still likely to consider basketball a personal leisure activity given their involvement in the co-recreational intramural program.

\section{MULTIPLE SELF IDENTITIES}

Given that identities are dynamic and situational, it is often the case that a single individual may have more than one identity at any point in time (Jones and McEwan 2000). Before one has identities occurring simultaneously, however, he or she must first create or form those identities. As stated, leisure, and more so, serious leisure, is an environment that helps create those identities as one is socialized into a leisure activity (Haggard and Williams 1992; Shaw, Kleiber, and Caldwell 1995; Jun and Kyle 2012; Jun et. al 2015). Oftentimes, identities are formed through the interaction piece of socialization, especially among college students (Kaufman and Feldman 2004) and in leisure environments (Williams 2002). As individuals enter into a leisure activity like intramural basketball, they are thrust into inevitable interaction with others in those same surroundings. In that leisure environment, there are individuals who hold certain identities and not others; interacting with those individuals with different identities is how new identities are created (Kaufman and Feldman 2004). 
Identities created may also be maintained or changed as one is socialized through the leisure activity (Haggard and Williams 1992; Shaw, Kleiber, and Caldwell 1995; Jun and Kyle 2012; Jun et. al 2015). Haggard and Williams (1992) found that part of choosing and continuing to play a leisure activity like intramural basketball is choosing to affirm or deny present identities, as well as continuing to create new ones. Once again, this is done through interacting with individuals with similar and different identities (Kaufman and Feldman 2004).

An identity that may be created and/or maintained or changed in the leisure environment of co-recreational intramural basketball is one's athlete identity; whether the identity will exist before the player joins an intramural basketball team depends on his or her previous athletic experience. Gender identity, on the other hand, may not need be created but maintained or changed as one is socialized into and through the leisure activity given the identity's pervasiveness in everyday life. Whether created or maintained or changed, the existence of an individual's multiple identities will make prioritization of either the athlete or gender identities inevitable.

Given that identities are created and maintained or changed through symbolic interactionism, this framework explains the prioritization of those identities as well (Charon 2007). Symbolic interactionism involves five central ideas:

1. Humans are constantly involved in social interaction;

2. Humans are constantly involved in thinking;

3. Humans are constantly defining the situations they are in;

4. Humans are acting based on the present; and 


\section{Humans are active beings (Charon 2007).}

When looking at supported or suppressed identities, frontstage or backstage identities (Goffman 1959) are explained based on the interactions that men and women face when playing with or against members of the same and opposite sex because "... the creation of identity is thought to arise through social interaction...", as previously indicated (Charon 2007, 24). Given that environments are always being redefined, symbolic interaction explains why certain situations, and thus connected interactions, encourage the emergence of certain identities, like the athlete and gender identities, and for certain players. Because of the prevalence of athlete and gender identities emerging in certain situations, researchers have looked at both athlete and gender identities in-depth, discussed below, so analyzing each one alone is paramount before looking at the level of significance and intersection of both as this study will do.

\section{ATHLETE IDENTITY}

Defining athlete identity may run counter-intuitive given that one's own definition of their athlete identity is personal and is likely to vary situationally. However, generally speaking, one's athlete identity is their "identification with the athletic role, acknowledging that [they] may have varying degrees of identification with this role" (Falls and Wilson 2012, 574-5). Thus, Falls and Wilson (2012) claim that while all corecreational intramural basketball players may claim this identity as one of their own, whether after creating or maintaining or changing the identity, each player is likely to have a different level of connectivity to being an athlete. 
One factor likely to cause this connectivity difference is gender. There may be group differences in each gender's association with the athlete identity. Perhaps the differences are related to actual and perceived constraints to participation in a predominantly men's domain. Although those gender constraints may be alleviated by the development of recreational capital, described below, those constraints still exist and in three forms: intrapersonal with regard to internal constraints such as lack of selfconfidence; interpersonal in reference to social constraints such as lack of friends with whom to participate; and structural as far as environmental constraints such as a lack of facility access (Crawford and Godbey 1987; Son, Kerstetter, and Mowen 2008). Naturally, men and women face constraints within each category, but women face constraints of each kind more often (Son et. al 2008). For example, women more frequently face the intrapersonal, internal constraints of negative body image and belief of appearance (Liechty, Freeman, and Zabriske 2006). In another reinforcing example, Jurczyk's (1998) study found that due to the context of women's lives, many women do not find time for personal activities, like leisure, thus dwindling the pool of women for women to play with and increasing their interpersonal constraints toward leisure. Fortunately, if women do create recreational capital, these constraints are more likely to be alleviated.

Another cause of varying levels of athlete identity association is the amount of skill, knowledge, and experience of a player in the leisure activity (Stebbins 2001). As discussed, a player with more of any of these three aspects of a leisure career is more likely to consider co-recreational intramural basketball a serious leisure activity. Further, 
when a player considers a leisure activity to be that of serious leisure, he or she is more likely to have a stronger connection to an identity associated with the activity, or athlete identity in co-recreational intramural basketball (Stebbins 2001).

Perhaps differences in athlete identity significance are only partially explained by gender constraints and differing levels of leisure proficiency. Adhering to an athlete identity also depends on a participant's position on the specialization continuum mentioned earlier in relation to serious leisure (and higher levels of proficiency). If Bryan's (1977) original conceptualization of RST is applied to intramural sport, when a participant falls on the highest, or even second-highest, level of the recreational specialization ladder, they are almost certain to consider being an athlete one of the, or even the, most important of their identities. Thus, if a participant voluntarily engages in co-recreational intramural sports, they are likely to exhibit a high level of commitment, be a technique or technique-setting specialist, and therefore consider the athlete identity highly important. This relates to the more recent uses of Bryan's (1977) theory as well: if a participant chooses co-recreational sports, they may be more likely to show behavioral, cognitive, and affective tendencies toward the leisure activity and therefore, associate more strongly with the athlete identity (Jun et. al 2015).

\section{GENDER IDENTITY}

Being an athlete is likely to be far from the only status being managed when playing co-recreational intramural sports. Gender identity is "the way in which being feminine or masculine, a woman or a man, becomes an internalized part of the way we 
think about ourselves" (Ryle 2012, 120). As a man or woman creates his or her gender identity, likely to happen long before entering co-recreational intramural basketball according to Kohlberg (1966), he or she learns how to enact that identity in different environments. In sport and leisure, men and women are often able to show their gender identities differently. This reflects upon how they have been socialized to view different gendered norms, or social guidelines on what is appropriate for masculine and feminine behavior (Ryle 2012). The showing of gender identities is called gender expression, gender performance, or "doing gender" (Goffman 1959; West and Zimmerman 2010). Doing gender is all about how a man or woman behaves and how that behavior is attributed to his or her identity as a man or a woman, which appears reliant on a gender dichotomy that may not exist but continues to be the standard for co-recreational intramural basketball. There are assumptions, or norms, that state how a man or woman should act according to his or her gender. Many of these assumptions are related to the constructed concepts of masculinity and femininity.

Depicting aspects of masculinity and femininity often hinges not only on the norms associated with the gender, but as stated, also on the environment in which one is behaving. Basketball is a predominantly masculine sport (Hanson and Kraus 1999; Birrell 2000; Stephens 2004; Chand 2005; Grubb and Billiot 2010; Walker and SartoreBaldwin 2013). Many men and women who participate note that they were socialized, and therefore taught about gendered leisure norms, into the sport when they were young (Messner 2012). The difference between socializations is quite different for young boys and girls who play basketball. Instead of femininity being encouraged in 
sport, girls often encounter an internal conflict between socialization processes as a girl and as a basketball player: femininity versus masculinity in sport (Malcolm 2006; Zapico, Tuero, Espartero, and González-Boto 2014). Thus, with socialization into basketball, boys are encouraged to play rough with the opposing team, which suits their needs for masculinity purposes but girls find this encouragement to be counter-intuitive with their socialization into orthodox femininity that encourages women to lessen the aggression with which some sport is played (Krane, Choi, Baird, Aimar, and Kauer 2004; Schippers 2007).

One way in which women may overcome this conflict between femininity and the masculine nature of athletics is by developing recreational capital, or "that which is needed to have both a preference for a particular leisure activity and be able to transform that leisure activity into actual participation" (Auster 2008, 318-319). Thus, as women identify basketball as one of their leisure preferences, having variants of recreational capital (e.g. knowing someone who participated in that leisure activity or having a strong supportive environment filled with individuals or socialization agents who encourage participation in that leisure activity) is likely to influence their socialization into, or the process in which individuals' gain entry into a leisure activity, and socialization through, or the process in which individuals are further developed through participation in a leisure activity, recreational basketball (Ruddell and Shinew 2006). While men may also have recreational capital, it a question of utilization: men may not need to utilize their recreational capital to cope with the tension between masculinity and the nature of athletics. Because entering into the realm of athletics is 
easier for men than women (Birrell 2000), they may not need to draw on their networks of men athletes to help get them involved, whereas that may be the exact case for women. Regardless of the intent behind socializing boys who become men and girls who become women into basketball, players are often taught to enact their gender according to the norms associated with his or her gender, thus masculinity or femininity, and the environment in which they are portraying that identity, such as in a corecreational intramural basketball game, regardless of any conflicts.

When discussing masculinity, it is necessary to address Connell's $(1995,2005)$ hegemonic masculinity. Hegemonic masculinity is defined as "white, rich, and heterosexual" (Hurtado and Sinha 2010, 101) but more generally, "the configuration of gender practices which embod(y) the currently accepted answer to the problem of legitimacy of patriarchy which guarantees (or is taken to guarantee) the dominant position of men and the subordination of women" (Connell 1995, 77). Both Hurtado and Sinha (2010) and Connell (1995) state that hegemonic masculinity is an ideal that men strive to reach in order to be seen as most masculine, though many fall short given that hegemonic masculinity is not represented in a majority of men (Connell 2005).

There are many ways in which men strive for hegemonic masculinity, one of which is often seen in the arena of athletics. Men may choose to like sports because, not only is it an inherently masculine domain, but "...it's the easiest way to choose 'guy' over 'gay'--and make sure everyone gets the right idea about them" (Kimmel 2008, 128; Hanson and Kraus 1999). This provides another characteristic of hegemonic masculinity: heterosexism. Men must not be, or appear to be, homosexual if they are to be in the 
most masculine condition. In order to prove their heterosexuality, and thus their hegemonic masculinity, men will distance themselves from any trait that could be perceived as feminine because "gay men who are seen as queer and effeminate are granted no space whatsoever in what is generally considered to be a masculine preserve and a macho enterprise (of athletics)" (Hekma 1998, 2; Gagné and Tewksbury 1996; Anderson, Magrath, and Bullingham 2016). This may be another reason why Stephens (2004) found that men intramural basketball players have a higher tendency to want to hurt an opponent than their women counterparts. This urge of aggression may be related to men wanting to prove their hegemonic masculinity by inflicting pain which may result in their distancing themselves from feeling pain, an aspect of athletics often assumed to be discussed by women (Hanson and Kraus 1999; Malcolm 2006). Showing no signs of pain/weakness and instead being aggressive is important in portraying one's hegemonic masculinity, as it is part of following David and Brannon's (1976) rules of "Being a Sturdy Oak" and "Giving 'Em Hell" to establish masculinity. In addition to this rule of "Being a Sturdy Oak," where one is tough and emotionless, and "Giving 'Em Hell," where one is aggressive, one must also abide by the remaining two rules: "No Sissy Stuff," where all that is linked to femininity, like acknowledging pain/weakness and avoiding acts of aggression, is prohibited and "Be a Big Wheel," where one is successful (David and Brannon 1976; Jakupcak, Lisak, and Roemer 2002; Smiler 2006).

On the other end of the spectrum from hegemonic masculinity is the hegemony of femininity. Just as there are gender identity expectations for men, there are those for women. As mentioned, femininity and sport may come in conflict. A possible 
explanation may be the expectations associated with normative femininity and the way in which women strive to meet those expectations. A few expectations of orthodox femininity are to be heterosexual, conservative sexually, and understand their lack of representation in authority positions (Kimmel 2013). If women do not follow the "rules" of hegemonic femininity, they may be labeled with negative statuses of femininity. Each contaminated status is associated with a more masculine quality, thus showing that the woman was not doing gender properly and has brought the classification upon herself. Examples, paralleling examples of expectations, include lesbian, for desiring women; slut, for showing sexual prowess; and bitch, for commanding authority (Schippers 2007).

\section{GENDERED COMMUNICATION}

According to Wood (2013), communication, the second major focus of this study, is systemic, meaning that the context and the broader culture in which the communication occurs is important for that context influences the communication that exists. Within the context of intramural basketball, and specifically co-recreational basketball, there are players of the same and opposite sex; both men and women players are part of the context that influences communication. The broader collegiate culture is also influential on the communication that exists during intramural events. The way collegiate men and women are perceived will aid in dictating the way men and women players talk to and about one another when participating in this leisure activity. The similarities and/or differences in communication strategies by gender apply to leisure/recreational sport specifically as men and women use the collegiate culture's 
perspective to relate to one another with verbal and non-verbal gestures that impact how they play co-recreational intramural basketball with and against participants of the same and opposite sex.

Once the context and broader culture have been taken into account by corecreational intramural basketball participants, there are several aspects of feminine and masculine communication that may be used as part of a participant's gendered communication strategy, although these differing aspects may not be unique to a particular social setting. Feminine speech is characterized by the drive to maintain relationships with others (Johnson 1996; Hudson 2001), establish equality between people (Hall and Langellier 1988), support others (Guerrero, Jones, and Boburka 2006; Mulac 2006), sustain a conversation (Taylor 2002), and be responsive (ChathamCarpenter and DeFrancisco 1998) (Tannen 1991; Wood 2013). Women are also likely to be more tentative when speaking on a topic where her opinion is openly displayed (Mulac 2006; Wood 2013). Men, on the other hand, are more likely to use their communication to establish status and control (Mulac 2006); display knowledge on a subject (Leaper and Ayres 2007); command the conversation (Aries 1987; Crowston and Kammeres 1998; Mulac 2006); be assertive, direct, yet abstract (Murphy and Zorn 1996; Wood, Christensen, Hebel, and Rothgerber 1997; Mulac 2006); and less emotionally responsive (Guerrero et. al 2006) (Wood 2013).

Verbal speech is not the only type of communication to be focused on in this study. In fact, nonverbal communication is often the type of communication that "reproduces or challenges images of femininity and masculinity and male and female" 
(Wood 2013, 140) (Anderson 2008). Thus, nonverbal communication is an important component of communication in general as it accounts for $55 \%$ of all communication, but also of sport culture as it is more spontaneous and uncontrollable in games than verbal communication (Preja 2013). In addition to the content-level differences in gendered verbal communication, Wood (2013) noted the values associated with the gender differences in non-verbal communication. With their nonverbal communication, women are said to value communality while men value agency (Wood 2013).

When discussing theoretical differences in gendered communication, what accompany those differences are theories that may explain their existence. Given the previous emphasis on symbolic interactionism and social interaction, the interactionist approach of doing gender (discussed as a way of portraying one's internalized gender identity) proves helpful in discussing gendered communication strategies as well (West and Zimmerman 2010; Ryle 2012). Part of doing one's gender is integrated in language use (Stokoe 2003). Therefore, there is importance in studying the connection between doing one's gender and language use, as each may be used to demonstrate the other.

Although there are theoretical differences in gendered communication, contemporary studies have noted that those expected differences do not always come to fruition. When studying soccer and volleyball, Sullivan (2004) found no differences in communication by each gender, but acknowledged that these findings ran counter to expectation and other research claiming the existence of difference. For example, Canary and Hause (1993) found in their meta-analysis of many studies in search of 
similarities or differences in gendered communication that differences in verbal communication by gender existed, even if the differences were only moderate.

The research projects within Canary and Hause's (1993) meta-analysis, and others, naturally found differences as well but claimed they were of larger substance than Canary and Hause (1993) portrayed them to be, especially in certain situations (Dindia and Allen 1992; Duck and Wright 1993; Aries 1996; Timmers, Fischer, and Manstead 1998; Fehrs, Baldwin, Collins, Patterson, and Benedict 1999; Kinney, Smith, and Donzella 2001). For example, although not in sport, Kinney et. al (2001) found that gender differences were striking when looking at how men and women college students verbalized anger and aggression.

Given that both forms of communication are important, it is pertinent to mention that non-verbal gendered communication strategies are found to be extremely different (Hall 1998). In sport specifically, similar findings are the result, claiming larger than moderate verbal and significant non-verbal differences in gendered communication (Kneidinger, Maple, and Tross 2001; Sullivan and Feltz 2003). 


\section{CHAPTER 3: RESEARCH METHODOLOGY}

Using a qualitative approach, I captured the fluid aspects of theoretical processes as I studied participant identities and gendered communication strategies in the specific leisure environment of co-recreational intramural basketball. Specifically, I used a grounded theoretical approach, or a system that identifies patterns from which concepts are built and then threaded into a theoretical framework to explain the experience being studied (Charmaz 2014). First, this context was appropriate to study given the multiple identities that participants were likely to be aware of, and therefore ranking, while playing; additionally, given the co-recreational presence in the environment, participants were likely to be aware of any similarities or differences in gendered communication that existed given their exposure to verbal and non-verbal communication between teammates and with opponents. Second, this approach was best because in-depth interviewing allowed me to "learn to see the world from (a) perspective other than my own" (Rubin and Rubin 2012, 3) and ask follow-up questions of the interviewees. Furthermore, non-participant observation of games once interviews had been conducted allowed me to triangulate the perspectives gathered from the interviews with what occurs in an actual game (Blumer 1986).] This aspect of seeing others' perspectives is especially important as I have extensive experience in this particular leisure environment. 
Before beginning interviews with participants, I explained to them that I played single-sex and co-recreational intramural basketball during my collegiate experience. I played single-sex intramural basketball for two years and co-recreational basketball for five years: one year of single-sex and four years of co-recreational basketball at Hanover College where I completed my undergraduate degree and one year of both leagues at the University of Louisville, the institution where I am working on my Master's degree and that serves as the site of this study. It was important to inform participants of my intramural background in order for them to feel comfortable using technical terms related to intramural sports and to foster rapport (Guest et. al 2013).

It was also important to disclose my membership in the study setting. Given my full participant status in the 2016 co-recreational intramural basketball league, I had complete membership, although I did not maintain a researcher role while the league unfolded, in the study setting (Adler and Adler 1987). Due to there not being a league going on while the interviews were conducted, the interviewees referred to the most recent league, given participation in the 2016 league was required for their participation in the study as is further discussed below. My complete membership in the study setting, and particularly in the league of discussion, aided in my receiving entrée into the field, but also raised difficulty, as discussed hereafter, in terms of creating unbiased relationships with interviewees; in order to do so, I did my best to take a fresh perspective as a researcher and change previous relationships if necessary to maintain strong researcher/interviewee relationships (Adler and Adler 1987). 


\section{SAMPLING}

Through an informal interview, an overseer of the intramural sports program at the University of Louisville, a large, public, Midwestern university that served as the study site, provided participation statistics for co-recreational intramurals as a whole, but also specifically for intramural basketball. This helped show the demand increase for this leisure activity at the University of Louisville, though it is not generalizable to other institutional co-recreational intramural basketball leagues' participation rates over time. In the academic year of 2011-2012, a mere 643 students participated in co-recreational intramural sports (compared to the 7,109 men and 1,826 women who played all intramural sports and out of the 21,153 enrolled at the University of Louisville), with only 21 of those students participating in co-recreational basketball (compared to the 861 men and 103 women who played single-sex basketball) (“Common Data Set 20112012" 2012; Peterson 2016). Accelerating to the most recent academic year of 20152016 , the number of participants in all co-recreational sports rose to 880 (compared to the 6,672 men and 1,990 women who played all intramural sports and out of the 21,295 enrolled at the University of Louisville), while the number of co-recreational basketball players jumped to 153 (compared to the 957 men and 120 women who played singlesex basketball) where $41.83 \%$ of those basketball participants were women ("Common Data Set 2015-2016" 2016; Peterson 2016).

These statistics aided in my method and sampling decision making. I conducted all interviews in the fall 2016 semester. I used purposive sampling to recruit participants 
who were familiar with the cultures of intramural basketball, specifically that of corecreational basketball, and have been involved in the last year in a co-recreational intramural basketball league at the University of Louisville. It should be noted that a selection bias may be present given that participants who choose to play co-recreational intramural basketball instead of or in addition to single-sex intramural basketball may not be representative of the larger intramural basketball participant population. Regardless of the possible selection bias, there was much to be gained by sampling, and specifically sampling purposively, from this population. Purposive sampling is sampling on "the basis of knowledge of a population, its elements, and the purpose of the study" (Babbie 2013, 187). I emailed team captains of the 2016 co-recreational intramural basketball league at the host university, with assistance from the Department of Intramural Sports, in order to begin recruiting participants.

When contacting team captains, I initially asked each to be a participant in my study. Regardless of their decision to participate, I asked them to provide their teams with my contact information and study description. The captains requested that their teammates contact me if they were willing to be interviewed. Given that there were twelve teams in the 2016 co-recreational intramural basketball league, I contacted twelve head captains, whose information was available to me as a player in the league but also per the agreement I had struck with the Department of Intramural Sports at the University of Louisville. Contacting all twelve captains permitted a more diverse sample than if only one captain and his/her entire team were interviewed. After contacting the captains and having the captains contact their teammates, I began interviewing those 
who volunteered. Having few true volunteers, I requested names from interviewees of teammates or opponents that may be willing to be interviewed. I reached the total sample through purposive sampling, as mentioned, but also through snowball sampling, as just described. I interviewed three to five members of each team that participated in the study, which added up to seventeen total interviews with past co-recreational intramural basketball players from four of the twelve teams; teammates are shown in Table 4.1 below. I stopped interviewing after the seventeenth interview because, not only were names of referred interviewees beginning to repeat (Ng and Coakes 2013), but I felt as though I had reached theoretical saturation, or the situation where interview results start repeating across all key demographic groups of interviewees (Guest et. al 2013). Key demographic areas of interest included, but were not limited to, gender, race, employment status, intramural experience level in years, and high school player status. I conducted the number of necessary interviews needed to address the central phenomena of this study, which were identity prioritization and gendered communication. 


\section{Table 4.1. Participant Subgroups Based on Team*}

\begin{tabular}{|l|l|l|l|}
\hline A & B & C & D \\
\hline Carl & Greg & Mason & Patrick \\
\hline Dana & Bob & Tommy & Matthew \\
\hline & Natalie & Monica & Kelsey \\
\hline & Penelope & Carmin & Chelsea \\
\hline & Willow & Lisa & *Teams are lettered in no \\
& & & particular order. \\
\hline
\end{tabular}

All Interviews were done in person and on campus. Being face-to-face allowed for more conversation, as well as the observance of any physical aspects of the interview. In the interviews, I took note of these physical descriptions, such as the participant shifting in their seat due to being noticeably uncomfortable, any emotional expressions made by the interviewee, etc. In order to conduct the semi-standardized interviews for approximately twenty to forty minutes, I constructed an interview guide (attached as an appendix).The questions that appeared on the guide were created in order to address the central phenomena and sensitizing concepts of this study. The sensitizing concepts were as such: identities, masculinity, femininity, and communication. I was also interested in the leisure environment that may have triggered identities, contextualized negotiation strategies, and shaped subsequent interactions, many involving gender. 
In order to address the first research question about managing multiple identities when playing co-recreational intramural basketball, for example, I asked "Tell me about how you demonstrate or hide your gender identity while playing co-rec intramural basketball?" This question got respondents discussing their gender identities and expressions. Interpreting gender identity prioritization was not as difficult as expected as many participants commented on their own gender identity's level of importance, specifically with regard to the environment and interactions that led them to place or downplay priority on their gender identity. I was interested in other identities as well, which is why I asked respondents to rank their multiple identities when playing co-recreational basketball and describe how they would feel if a certain identity was lost or diminished.

Further, in order to understand gendered communication strategies, I asked respondents: "How would you react when a teammate of the opposite sex hits a three pointer?" I asked about teammates of the opposite and same sex in order to analyze whether or not the communication used by the participant is gendered. It was my aim in this question to both draw out whether communication is gendered, but also to generate the verbal and nonverbal responses of teammates' reactions to the success of another teammate depending on the sexes of both players. In doing so, I was able to answer the larger question of how players of both sexes use gendered communication strategies to negotiate masculine leisure environments involving men and women players, discussed below. 
The population in this study was all co-recreational intramural basketball players. The seventeen voluntary participants of the 2016 co-recreational intramural season served as a sample of the population. As noted, the participants were categorized based on key demographics, with gender being the most important. In addition to gender, the participants were split into subgroups based on personal skill level stated by the participant and triangulated by others on his or her team. Based then on the gender and skill level, the seventeen interviewees were split into four subgroups as seen in table 4.2 below. The subgroups proved beneficial for the categorizing of participants, but also in deriving patterns in themes. As discussed below, the variations on themes were rooted in the subgroups noted here. Given the sampling methods of purposive and referral natures, the study is likely to be generalizable to co-recreational intramural basketball players at large, Midwestern, public universities like the University of Louisville.

Table 4.2. Participant Subgroups Based on Gender and Skill.

\begin{tabular}{|l|l|l|l|}
\hline $\mathbf{1 G}$ & 1B & 2G & 2B \\
\hline (Men; High Skill) & (Men; Low Skill) & (Women; High Skill) & (Women; Low Skill) \\
\hline Carl & Bob & Dana & Penelope \\
\hline Greg & Tommy & Cassie & Willow \\
\hline Patrick & Matthew & Kelsey & Chelsea \\
\hline & & Ellie & Lisa \\
\hline & & Monica & \\
\hline
\end{tabular}




\section{DATA ANALYSIS PROCEDURES}

After the first audio-recorded interview was conducted and transcribed, I analyzed the interview and each subsequent interview as I continued collecting data. I used the constant comparative method throughout the data gathering process in order to continually inform my interview guides and make adjustments as necessary in order to best develop the themes proving most pertinent, as well as to encourage elaboration by interviewees on the sensitizing concepts of interest: identities, masculinity, femininity, and communication (Guest et. al 2013; Charmaz 2014). Information was grouped in emerging categories and concepts in order to aid in the construction of theory. I gauged authenticity by looking for opportunities of triangulation, or crossreferencing for truth from multiple interviewees (Golafshani 2003) and from observations of games (Blumer 1986).

After all the interviews were conducted, transcribed, and initially analyzed, I began looking for themes and codes under the themes. Knowing (from the initial analysis) that the themes would vary by subgroup, as mentioned above, the first step in data analysis was to divide the physical transcriptions into their interviewee's respective subgroup. Next, I read through subgroup 1G, or the men with high skill. After the first reading of the four men's transcripts in subgroup 1G, I went through the transcripts again in order to make theme headers of the interview questions to indicate possible themes. I then read through the interview transcripts again to note the types of 
responses to the theme headers to indicate possible codes. During each reading, I made note of excellent or telling quotes. I repeated all of these steps with groups 1B, 2G, and then $2 \mathrm{~B}$.

After making note of all the possible themes and codes, I pulled together the major themes and their codes that were most connected to the research questions of this study. I narrowed it down to three major themes for each of the major topics in this study: serious leisure, multiple self identities, and gendered communication. To accentuate the themes and codes chosen for each of the three topics, I selected the best quotes from the transcripts, with each participant having at least one chosen quote.

Maintaining ethical procedures is always an important task when conducting field research. As far as consent issues, I had the interviewees fill out an informed consent form to ensure that all participation was voluntary. Pseudonyms were given to all participants to ensure anonymity and confidentiality.

\section{LIMITATIONS}

Having played with and/or against some participants in the co-recreational intramural basketball league during my first year of graduate school may have influenced data collected as some participants may have formed opinions of me that may affect their interview responses. I tried to minimize those biases by asking interview questions in an impersonal way so as to take away from the fact that the interviewee and I may have been in a similar situation in the past. Regardless of my 
having played with or against an interviewee or not, there was potential for bias in data reporting, data collection, and myself as a past player and the interviewer (Babbie 2013). To prevent biased data reporting and collecting, I enacted fair sampling techniques, as discussed. I also attempted to eliminate my own biases as a player and interviewer by rephrasing responses of interviewees in order to confirm the intention of their answers to interview questions.

Having interviewed participants who have participated in at least the past year may have led to some errors in recollection given that I asked them to recall memories from six or more months prior to the interview. An argument can be made to interview only participants who are actively involved in a league during the time frame of the interviewing, especially considering the fact that many participants may have tried to produce responses of social desirability, or tell me what they think I wanted to hear or what they believed was the proper answer according to societal norms (Herbert, Ma, Clemow, Ockene, Saperia, Stanek, Merriam, and Okene 1997). However, an argument can also be made for allowing breadth in an interviewee's amount of experience of which can be drawn upon. "Qualitative researchers are more likely to look at events as they unfold over time, looking at chains of causes and consequences and searching for patterns- not just looking at the last city council meeting..." (Rubin and Rubin 2012, 6). As such, I let participants give examples from or elaborate on their experiences of multiple seasons, rather than just focus on the last game or the current season. 


\section{CHAPTER 4: FINDINGS}

\section{SERIOUS LEISURE}

Having asserted, with the help of previous literature, that basketball is a predominantly masculine sport, it seemed necessary to see if that idea still holds with participants in a current co-recreational intramural basketball league. When asked if the environment was indeed considered masculine, almost all interviewees said that it is one of masculine description. Monica, subgroup 2G, went as far to say that, “...guys view girls not as good at sports..." so during games, "...guys aren't involving girls. It's kind of like, oh, it's just a guy sport." Chelsea and Penelope, both subgroup 2B, agreed with Monica in saying, respectively, "I feel like... I'm not contributing as much because it's like a boy-run sport"; "I mean, it's, it's a sport for women but it's a male dominated sport for sure... cause unless the girls are super good, you're not gonna get the ball as much because, I mean, they'll do it on their own." Given the strength of statements from these women players, as well as those from the men players, it appears that while more women are playing basketball, it is not lessening the masculine hold on the environment.

Regardless of the masculinity associated with co-recreational intramural basketball, men and women are still playing, and, as mentioned, at an increasing rate. If 
Stebbins (2005) is correct in his definition that leisure is activity in which participants find enjoyment and self-confidence, then co-recreational basketball participants in all subgroups, regardless of skill, should have answered with similar reasons as to why they participate in this specific leisure environment. When asked why he played corecreational intramural basketball, Bob, subgroup 1B, said, "I love the game of basketball, and I figured it would be a good experience playing with other, ya know, another gender... and they (the girls on the team) needed guys. We didn't want to let them down, so we played." Here Bob reiterates Stebbins' (2005) idea of enjoyment in an activity to allow it to be one of leisure but adds another component of why one might play co-recreational intramural basketball that seemed to be repeated through multiple interviews: friends, whether women or men, needing more players. Cassie, subgroup $2 \mathrm{G}$, spoke of enjoyment but also of friends, though in a different way than Bob, when asked why she chose the league she did: "I played basketball all through high school and that was kinda like my sport, so I figured this would be a better way to connect with the people in my department." Stebbins (2005) is right in that students are playing corecreational basketball because they enjoy the sport, but they are also playing because they want to make their current friends happy or make new friends.

Given their reasons for playing co-recreational intramural basketball, it is a fair assessment that all participants consider the activity one of leisure, but as mentioned, each participant differs in their level of connection to the activity, thus varying their placement in the recreation specialization theory (RST), and more importantly, their identification with the leisure activity as one of serious or casual nature. Given that 
twelve of the seventeen interviewees played organized basketball in high school, those participants considered co-recreational intramural basketball as one of serious leisure as they all showed a long-lasting relationship with the activity based on, if nothing else, experience (Stebbins 2001). Of the remaining five, three of them stated their perseverance with the activity, pushing them into the serious leisure enthusiasts category as well (Stebbins 2010). The remaining two interviewees claimed to consider co-recreational intramural sports as a whole to be an activity of serious leisure, making basketball specifically more of a casual leisure pursuit for them.

Now that fifteen of the seventeen interviewees have been noted as those who would consider co-recreational intramural basketball a serious leisure pursuit, another aspect comes into play with regard to the stated masculinity that surrounds this leisure context. Even though this may be serious leisure for women players, does the predominant masculinity associated with basketball shape their roles and experiences in the co-recreational intramural environment? When asked who is more likely to play (as in the split of the five players on the court) in the co-recreational intramural basketball league (where the rule is that two women and two men must be on the court at all times for a team but the fifth player may be a woman or a man), Carl, subgroup 1G, said bluntly,

"I think for the most part, when you have co-rec, a lot of times it's three guys and two girls because honestly, guys are generally going to be your main players in co-rec... so like, a lot of teams just have girls because they have to have girls, and so like, it will be three guys running the show and then the girls will be out there because they have to be out there." 
When asked a follow-up as to why guys are "generally going to be your main players in co-rec", Carl said, "...because, it's like, you throw them (women teammates) the basketball, and they don't really know what to do with it anyway." Thus, the masculinity that is pervading the leisure environment is lessening the perceived role of women players, and while the women may not want to accept that this is the case, they do so as they feel they have no choice. When asked the same initial question as Carl on the split up of the five players on the court, Lisa, subgroup 2B, agreed with Carl that there are usually three men and two women. When asked why it happened that way, Lisa said,

"Because they (the men players) want to fill that (fifth spot) with somebody who's going to score, somebody who's going to defend the other team... and yeah, it's definitely because they (the men players) think that our skill set is just inadequate compared to theirs... we have to be, like, $100 \%$ perfect in order to even... slightly breach any kind of expectation they had of us... because even the lowestranking guy, they (the men players) still think is... better than all of us (the women players)."

Ellie, subgroup $2 \mathrm{G}$, agreed that men players are the ones that lower their expectations of women, stating: "When I was wide open in a lot of situations, like they (the men players) didn't even look at me to give me the ball and like, my, the other girls on my team too, I would notice it... they're (women players) a requirement and not really like an asset." While Carl and Ellie both comment on the men players thinking less of women players, Penelope, subgroup 2B, added that women players, including herself, think less of women players as well. When asked about her response to a male teammate making a three pointer, Penelope shrugged, claiming, "They're more likely to do it over the girls so... it's not as big of a deal." Therefore, basketball is indeed a 
predominantly masculine sport, yet women still play. They play knowing that some men are already thinking less of them as athletes; what's more, and what they may not know, is that even some women are thinking that as well.

\section{MULTIPLE SELF IDENTITIES}

When identities are dynamic and situational, as they are in a co-recreational intramural basketball environment, it is true that an individual may possess more than one identity at a given time. What is unique about basketball, and perhaps any other activity that is fast paced, is that an individual may be forced to prioritize instead of being aware of his or her multiple self identities simultaneously. Since a serious leisure activity can create or maintain or change an identity(ies), it is important to note that while I initially considered that participants may have a gender identity but not an athlete identity, it turned out that all participants had both, as shown below. It was in these findings that triangulating interviews and observations became beneficial; in the multiple self identities and gendered communication groups of findings, I note the results of both methods.

\section{ATHLETE IDENTITY}

All interviewees in this study began their co-recreational intramural basketball journey with their athlete identity, which in hindsight is not surprising given that so many of them played high school basketball and those that did not played other sports. When asked if he or she were an athlete, all seventeen participants said yes, that they were indeed an athlete. Most interviewees supported their statement that they were an 
athlete with a definition of what made an athlete. These definitions showed a mix of behavioral, cognitive, and affective qualities that varied with their own specialization in co-recreational intramural basketball, just as previous scholars predicted (Bricker and Kerstetter 2000; Scott and Shafer 2001; McFarlane 2004). What differentiated the corecreational intramural basketball participants was their decision, whether consciously or not, to show or hide their athlete identity.

As I spoke with each man, his answer as to whether or not he showed or hid his athlete identity ended up solidifying the necessity for the subgroups based on skill. All of the men in subgroup $1 \mathrm{G}$ stated that they hid their athlete identity in a co-recreational intramural basketball game, while the men in subgroup 1B claimed to have shown their identity in the same situation, as shown in table 5.1 below. For example, when asked whether he showed or hid his athlete identity when playing co-recreational intramural basketball, Mason, subgroup 1G, claimed: "I was definitely more apt to kind of hang out, and you know, get other people involved- get the girls more involved." Thus, playing with women encouraged Mason and his subgroup counterparts to rescind their athleticism, at least in part. Tommy, a representative of subgroup 1B, stated that, "I'd say you try to (hide your athlete identity)... but... when you... if you've played basketball your whole life, your play style is gonna come out eventually." Therefore, in the case of the men with less skill on the court, they did not feel as obligated to hide their athleticism. 
Table 5.1. Answer to Show or Hide Athlete Identity by Men Participant Subgroups

\begin{tabular}{|l|l|l|l|}
\hline $1 G$ & Hide/Show Athlete & 1 B & Hide/Show Athlete \\
\hline Carl & Hide & Bob & Show \\
\hline Greg & Hide & Tommy & Show \\
\hline Patrick & Hide & Matthew & Show \\
\hline Mason & Hide & & \\
\hline
\end{tabular}

The women's answers to the same question were less consistent within the subgroups than the men's, but still showed some consistency nonetheless. The women in subgroup $2 \mathrm{G}$ were a 4-2 divide on having hid versus showed their athlete identity in co-recreational intramural basketball games, as shown in table 5.2. Cassie and Carmin, both subgroup $2 \mathrm{G}$, agreed, with the respective statements, on having hid their athlete identity in this particular serious leisure environment:

"I think definitely (hid)... women play differently when they play co-rec basketball... they sometimes will play less aggressively or feel like they're less of a key player on the floor... and I certainly did that and I seem to observe that with other women I was playing with"; and "I might be a little more relaxed playing with them (the men) because I know that, like, I can just go stand in a certain spot and they'll give me the ball...."

Thus, more women players with more skill felt as though they hid their athlete identity.

Although outnumbered, two skilled women players claimed to show their athlete identity when playing basketball with men. Ellie, subgroup $1 G$, was one of those women: 
"I just... I don't know, like, I try not to be lazy with them because I try to keep up and show that I'm, like, worthy of like... like, when they're (the men) guarding girls, they, like, don't really guard them, and to me, that's, like, an insult so, like, I wanna, like, play and score... enough to where they (the men), like, actually have to guard me. That's, like, my goal when I'm playing with guys."

Ellie's perspective aligned more with the women of subgroup $2 \mathrm{~B}$, where three of the four women stated that they, too, showed their athlete identity when playing with men in an intramural basketball league (also shown in table 5.2), often to overcome the lack of respect they received from their men teammates and opponents as suggested by Ellie above.

Table 5.2. Answer to Show or Hide Athlete Identity by Women Participant Subgroups

\begin{tabular}{|l|l|l|l|}
\hline 2 2G & Hide/Show & 2B & Hide/Show Athlete \\
\hline Dana & Hide & Penelope & Hide \\
\hline Cassie & Hide & Willow & Show \\
\hline Kelsey & Show & Chelsea & Show \\
\hline Ellie & Show & Lisa & Show \\
\hline Monica & Hide & & \\
\hline Carmin & Hide & & \\
\hline
\end{tabular}


Observations of multiple co-recreational intramural games proved that the comments made by the interviewees regarding the hiding or showing of athlete identity were mostly correct. In watching those games, I noticed that men and women with skill are more likely to hide their athleticism, just as stated in the interviews. Also in line with interview responses, men and women with less skill are more likely to show this identity. Although this was the case throughout most of the games I watched, men and women with skill would diverge from their typical willingness to hide their athletic identity when the games were close. Thus, unless the game was on the line, men and women stuck to their usual hiding or showing of their athletic identity depending on their level of skill, just as they said they did in their interviews.

\section{GENDER IDENTITY}

Being an athlete was not the only identity found to be of importance to corecreational intramural basketball players. Like the athlete identity, all seventeen participants noted that they were aware of their gender identity and made a decision, again consciously or not, to have hid or showed that identity in the context of discussion. Unlike the athlete identity, there was consensus among all but one participant (and all participants during game observation) in that the gender identity of a participant was shown through gender performances during co-recreational intramural basketball games, as shown below in Table 5.3 and 5.4. With this identity, there was not a division between genders or skill levels, although the reasons did vary by gender. 


\begin{tabular}{|c|c|c|c|}
\hline $1 G$ & Hide/Show Gender & $1 B$ & Hide/Show Gender \\
\hline Carl & Show & Bob & Show \\
\hline Greg & Show & Tommy & Show \\
\hline Patrick & Show & Matthew & Show \\
\hline Mason & Show & & \\
\hline
\end{tabular}

Table 5.4. Answer to Show or Hide Gender Identity by Women Participant Subgroups

\begin{tabular}{|l|l|l|l|}
\hline 2G & Hide/Show & 2B & Hide/Show Gender \\
\hline Dana & Show & Penelope & Show \\
\hline Cassie & Show & Willow & Show \\
\hline Kelsey & Show & Chelsea & Show \\
\hline Ellie & Show & Lisa & Hide \\
\hline Monica & Show & & \\
\hline Carmin & Show & & \\
\hline
\end{tabular}

Tommy, although in subgroup $1 \mathrm{~B}$, represents the men in both $1 \mathrm{G}$ and $1 \mathrm{~B}$ as he stated his explanation for having showed his gender identity in co-recreational intramural basketball games: “...you don't wanna be, like, that guy who's blocking all the girls' shots and whatnot... if a girl is guarding you, you're gonna notice. There's a 
difference." Thus, showing or performing one's gender identity was as easy as being aware of who you are guarding and who is guarding you. With that awareness comes a decision as to how to play, just as Tommy noted above.

In agreement with Tommy was Kelsey, subgroup 2G, though for a different reason and showing more overt gender expression as opposed to Tommy's internal awareness. Kelsey stated that she was so aware of her gender identity that she would even yell about it to her teammates, often men, that were ignoring her: "They (the men teammates) would just leave me wide open... (so I would just yell) 'Okay... I guess I'm just gonna stand here with no one guarding me!'." Here, Kelsey notes that being aware or showing one's gender performance can be explicit as well.

In discussing gender identity, one's masculinity or femininity is often a linked topic of conversation. As I asked about having showed or hid one's gender identity, I was surprised at the lack of mention of masculinity or femininity. Those concepts, however, did arise more naturally as I probed about the environment of co-recreational intramural basketball, which many interviewees did describe as being masculine. Further, concepts related to hegemonic masculinity and hegemonic femininity arose more subtly when I probed about men and women's reactions to other men and women players in certain situations. Often, the men reiterated their heterosexism, urges of aggression, and lack of pain, as shown in Bob's, subgroup 1B, statement about how men play basketball: "The males get more competitive and aggressive and hate losing... I think they (women players) notice that and respect that." While Bob discussed aggression, Tommy, also subgroup 1B, claimed that men do not feel pain when asked 
about what he would think when a woman teammate got hurt: "I think kind of the natural thing that comes to mind... is 'Oh, she's being a girl', like, 'Girls always get hurt', and like, 'That wouldn't have hurt any of us'."

While the men reiterated their attainment, or attempt to attain, hegemonic masculinity, there were concepts mentioned by interviewees about women's gender expectations or hegemonic femininity. When women were not heterosexual, it was mentioned; when women did not act sexually conservative on the court, it was noticed; and not only was the lack of heterosexism and sexual conservatism noticed, it was associated with a more masculine concept. Penelope, subgroup $2 \mathrm{~B}$, was a blunt interviewee, calling both the "lesbians" and the "sluts" (Schippers 2007), although not in those terms, out on their behavior inconsistent with hegemonic femininity. With respect to the lesbians, Penelope noted that, when asked if her women teammates showed or hid their gender identity,

"No, most of the girls are just like me. (Lesbian teammate)
wears basketball shorts (known for being worn usually by
men in intramural leagues) but that... I mean... I'm trying to
think of a better word than gay but... that's just, they're
(lesbian teammates) more on the masculine side
anyway...."

Thus, while not called a "lesbian" per se, Penelope noted her lesbian teammate's homosexuality and connected that sexual preference directly with masculinity. Penelope made a similar comment about women opponents that may be considered "sluts"; again, she did not directly call these women sluts, but noted their tendency to act against normative femininity on the court: “... you have some girls that, uh, stick 
their butt out, or... ya know, try to look cute for people watching... I just think girls who wear spandex (and stick their butt out) only do that to show the guys who are watching that, 'Hey. I have a big butt'." This time Penelope did not connect this lack of sexual conservatism to masculinity, but there is an underlying connection given that promiscuity is considered a more masculine trait.

\section{ATHLETE OR GENDER}

With identity prioritization being the first research question of this study, it was imperative to assess the co-recreational intramural basketball players' process of ranking their identities in this particular situation. Most of the men interviewees, 5 of 7, stated that they prioritized their gender identity in this particular leisure context while nearly all of the women interviewees, 9 of 10, ranked their athlete identity as most important over their gender identity, as shown in Table 5.5. These claims were only partially confirmed when tested by observations. Men players were seen prioritizing gender, but only when directly interacting with women teammates and opponents. Women were correct in assessing their own prioritization, as most were seen ranking their athlete identity above that of their gender. 


\begin{tabular}{|c|c|c|c|c|c|c|c|}
\hline $1 G$ & $\begin{array}{l}\text { Athlete } \\
\text { or } \\
\text { Gender? }\end{array}$ & $1 B$ & $\begin{array}{l}\text { Athlete } \\
\text { or } \\
\text { Gender? }\end{array}$ & $2 G$ & $\begin{array}{l}\text { Athlete } \\
\text { or } \\
\text { Gender? }\end{array}$ & $2 B$ & $\begin{array}{l}\text { Athlete } \\
\text { or } \\
\text { Gender? }\end{array}$ \\
\hline Carl & Gender & Bob & Gender & Dana & Athlete & Penelope & Athlete \\
\hline Greg & Gender & Tommy & Gender & Cassie & Athlete & Willow & Athlete \\
\hline Patrick & Athlete & Matthew & Athlete & Kelsey & Athlete & Chelsea & Athlete \\
\hline \multirow[t]{3}{*}{ Mason } & Gender & & & Ellie & Athlete & Lisa & Athlete \\
\hline & & & & Monica & Gender & & \\
\hline & & & & Carmin & Athlete & & \\
\hline
\end{tabular}

The most telling of quotes from the interviewees comes from Carmin, subgroup

$2 \mathrm{G}$, when asked whether her athlete or gender identity were more important to her;

though answering that her athlete identity was more important, she added as an

afterthought:

"I guess I would think about my, like, identity as a female because I wouldn't want them (men teammates) to think any less of me but I would think of my athletic identity because l've always identified as an athlete."

Carmin's answer proves that identities are situationally prioritized in that when playing with men she is more conscious of her athlete identity but that emphasis may be because of her awareness of her gender identity. 
Similarly to Carmin, Tommy, subgroup 1B, claims that gender is prioritized because of the situation that is co-recreational intramural basketball. When asked which identity was he was more conscious of, Tommy answered, "Gender... If a girl is guarding you, you're gonna notice. There's a difference." The difference he is referring to is based on whether he is being guarded by a man or a woman opponent. Because women opponents may be the ones he faces in this situation, Tommy, as well as many of the other men interviewees, focused on his gender identity instead of his athlete identity. Therefore, when asking how co-recreational intramural basketball players manage their multiple identities and statuses when playing with or against members of the same or opposite sex it has been shown that prioritization is done based on one's gender, regardless of skill.

\section{GENDERED COMMUNICATION}

Being made of verbal and nonverbal aspects, communication, and thus communication that was or was not gendered, was assessed through various questions with interviewees. The following situations were presented to both men and women interviewees: guarding a man or a woman and a man or woman hitting a three point shot, turning the ball over, and getting injured. I asked about a man and a woman to both genders of interviewees in all situations so all situations would show comparative answers except that of guarding a man or a woman; this situation proved irrelevant in terms of comparison due to men describing guarding men and women describing guarding women as "normal." All co-recreational intramural basketball players 
answered these questions as though they were in a game. In these answers, both verbal and non-verbal responses arose, allowing for evaluation of situational communication by gender. Participants who stated that the co-recreational intramural basketball league was masculine were also asked how they negotiated that environment, using their stated gendered communication strategies, given its importance as the second major research question of this study. A note should be made that given the type of responses these situations elicited from the interviewees, the tables that were used to illustrate previous findings proved unaccommodating in aiding in the explanation of the following findings.

\section{GUARDING A MAN OR WOMAN}

The first of these questions regarded how a man or woman player spoke about his or her verbal and non-verbal responses during his or her guarding a man or woman opponent. When asked this question, the men in subgroup $1 \mathrm{G}$ and $1 \mathrm{~B}$ did not describe verbal reactions to guarding a woman; this is not surprising given the lack of verbal interaction in this situation in real game time. Non-verbal gestures, however, were in abundance. Greg, subgroup 1G, stated that when he first realizes that he is now guarding a woman, his instinct is to act non-verbally by "switching" immediately. I asked why this was his reaction, and he said, “(because) I don't think I should be guarding a female, personally." Thus, guarding a woman made Greg uncomfortable enough to forcibly switch with someone else so as to not have to guard her. Bob's, subgroup 1B, non-verbal response to guarding a woman was not quite as drastic: 
"I kinda give them (women players) their space. I don't want to be up tight guarding them... I don't tend to play as hard of defense on them... You don't want to be too hard on them but you want to make it to where they don't feel as if... you're letting them score so you'll keep your hands out and make it a little difficult on them but not really like crazy pressure or anything (like you would if you were guarding a man)."

Although less extreme than Greg, Bob also made a point to acknowledge that there is a non-verbal reaction when guarding a woman that does not exist when guarding a man.

The women had varied responses when asked about their verbal or non-verbal response to guarding a man; these differences were related mostly to the woman's confidence in her skill level and not by actual skill level subgroup placement. Chelsea, though subgroup 2B, was more self-confident than Dana, subgroup 1G; this difference was seen in their respective responses to guarding a man: "I just try to keep the ball away from them, cut them off, yeah, stay low... just aggressive" compared to, "I'm probably going to call for help but I'm probably also going to try to defend them." Here, it is clear that both women may take the same approach non-verbally with their trying to guard the man, but Dana admits that she may have a verbal response as well in her calling out to her teammates for help defensively.

Given the communication styles discussed by the men and women interviewees for this situation, non-verbal, with verbal being rather nonexistent, communication does seem to be gendered here. When guarding a woman, men are likely to either leave the situation entirely or give her space while on offense. When guarding a man, women are likely to call for help but to also guard as well as they can. The strongest difference is in 
the non-verbal reaction where men lighten up their defense while women buckle down when guarding a member of the opposite sex; this was both stated in interviews and perceived during game observations. The similarity exhibited in this situation is internal in that both men and women assume that men are better than women, as is shown in the need for men to make it easier for the women or for the women to try to make it harder for the men to balance the game for both sides.

\section{MAN OR WOMAN TEAMMATE HITTING A THREE POINT SHOT}

In the second situation presented to the men and women interviewees, they were asked how they might respond verbally and non-verbally to a man or woman teammate hitting a three point shot. For this situation, the men and the women mentioned verbal and non-verbal responses, yet only the verbal responses were confirmed by observations. Patrick, subgroup 1G, spoke more of the verbal but also included associated gestures in his answer. Although only saying "Good job" to a man teammate who had just hit a three pointer, Patrick claimed to react this way to a woman teammate in the same situation: "(I'd yell) 'HELL YEAH!' I get really excited when a female teammate hits a three... it's, it's a huge deal. It's like 'YES! Good job!!!' I'Il start jumping. I'll get so excited. (In my head, I might think) 'Wow? Wow. That's impressive.'." Mason, subgroup 1G, agreed Patrick's increase in excitement for women compared to men. A "Good shot" would go to men teammates, while his reaction to women would escalate quickly: 
"Yeah. I get a lot more excited. I mean... I'll go clear across the court to give her a high five or tell her 'Good job', or I speak up a lot more.... So, say a guy hits one, and then three, four possessions go by, and then there's a time out, you're not gonna bring back up that play... but if a girl does it (hits a three), you might say, 'Hey, that was a good shot back there a couple minutes ago'."

Therefore, the men are likely to get overly excited both verbally and non-verbally when a woman teammate hits a three pointer.

Not much different from the men's answers were the responses, both verbal and non-verbal, of the women when reacting to a woman's three as compared to a man's three. Ellie, subgroup $2 \mathrm{G}$, said that she would, “... be excited that a girl scored. (She might think) 'Yay! She made us look good.'." Her verbal responses included a more excited "Good job" for women teammates doing good things, though not quite as excited as those exclamations from the men toward their women teammates. Switching to the non-verbal side of communication, Willow, subgroup $2 \mathrm{~B}$, said that when reacting to her man teammate's three pointer, “... maybe I make less of a gesture (of excitement than when a woman teammate hits a three)... like, you're a guy, maybe you should be able to hit more than a girl...." Willow, like Ellie, stated that perhaps she acts more excited for a woman teammate than a man teammate hitting a three pointer, although again, less excited than a man player would be in the same situation.

Connecting the communication from both genders of interviewees regarding the given situation shows that in this instance, the communication styles are again gendered. The level of excitement found in the way that each gender reacts to the female gender proves the gendered nature of verbal and non-verbal responses. When a 
woman teammate hits a three pointer, men teammates yell and bounce with

excitement, while women teammates get excited verbally and non-verbally, though not at the same level as the men. As indicated above, though the verbal responses of men and women were heard, the non-verbal claims of interviewees were not observed during the triangulation phase of this study. Instead of reacting with the gestures the players claimed they would make, both men and women players only clapped when a teammate of either gender hit a three pointer. Though this dilutes the level of gendered communication non-verbally, it does not impact the existence of verbal gendered communications strategies.

MAN OR WOMAN TEAMMATE TURNING THE BALL OVER

Thirdly, interviewees were asked of their reactions to a teammate, man or woman, turning over the ball, allowing for the other team to score in a close game. The lack of a verbal response toward a woman teammate turning the ball over as opposed to a stern remark being made to a man teammate in the same situation is telling, as in Mason's response:

"No. (I'm not going to say anything to her). I guess, I just feel more like... (an) asshole if I say something to her. I don't really care how the guys perceive me, but I don't want to... I guess it's, it's just a lot like looking like a jerk (that I want to avoid). I'm gonna look like a jerk if I get mad at a girl versus if I get mad at a guy, it's more accepted.... You can tell how, just like, backwards it is. The dude could suck, but if he does something that I don't like, then I'm much more apt to say something than... A girl could've played... and if she screws up, I'm probably not gonna say anything... even though it's obvious that this girl is much, much better than him." 
While the verbal reaction was quite different toward a man or woman negatively impacting the team, the non-verbal reaction was quite similar from men, including rolling one's eyes, sighing, or putting one's head down while getting back on defense.

Verbally, the women agreed with the men that they would not say anything to the opposite gender if they committed a turnover. The explanation, however, was quite different. Mason did not want to say anything to the women for fear of looking like a jerk, whereas Monica, subgroup 2G, did not say anything to the men for fear of feeling out of place:

“No. Definitely not (I'm not going to say anything to him)... just because I feel like the guys think they're better because they're guys so I wouldn't... I think they'd think I didn't have the place to say anything."

As for the verbal to teammates of the same gender, the men and the women disagreed as to how to approach the situation:

"(I'd say) 'Oh, it's alright!' Ya know, just making sure that they're not super down on themselves, cause I know that a lot of the girls that I play with would be, especially in a coed (co-recreational) situation... cause the guys get more upset about it... and you feel embarrassed."

As Kelsey, subgroup 2G, stated above, women felt the need to show, at least outwardly, compassion to women teammates who mess up in co-recreational intramural basketball leagues, contrasting the reprimanding approach of the men toward men teammates who make a mistake. With the outward, or verbal, expression taken care of, the women responded with the exact same non-verbal gestures toward the negative situation as the men: eye rolling, sighing, and keeping one's head down. 
With the non-verbal responses being identical, those gestures are not considered to be gendered communication. Verbal responses, specifically to that of the same gender, however, are gendered. While it is true that men and women agree not to say anything to each other when making a turnover, men do verbally acknowledge other men and women other women. Given that men use harsh criticism and women use constructive criticism, these styles are examples of gendered communication. Further supporting, though not paralleling, the claim of gendered communication styles was the viewing of co-recreational intramural basketball games. While women were indeed heard using constructive criticism after women teammate turnovers, men were heard joking with their men teammates who had just turned the ball over. This flippant verbal style contradicted the claim of using harsh criticism in the given situation. What may explain this difference, though, is that the games observed were not tournament games; the theory behind this being that men are more likely to match their claim to use harsh criticism if the game is considered important.

\section{MAN OR WOMAN TEAMMATE GETTING INJURED}

The last of the four situations that co-recreational intramural basketball interviewees were presented with is one of injury: How would you react, both verbally and non-verbally, to a man or woman teammate getting injured? The men respondents did not hold back when answering this question. When a man teammate got injured, Patrick, subgroup 1G, said that he would tell them, "Get up, you wimp!" Tommy, subgroup 1B, agreed with Patrick, as he claimed that he would tell his men teammates to "Suck it up." To women teammates, Patrick, Tommy, and most of their men 
counterparts claimed that they would ask if the woman was okay. Non-verbally speaking, Tommy summed it up by saying that he and other men would, “... probably (be) more likely to, like, be by her side, like help her with it" as opposed to just walking away from a man teammate with an injury unless, of course, they could tell it was an extreme injury for the man.

Verbally and non-verbally, the women contrasted the men in that they claimed to have a similar response to a man or a woman teammate getting injured. Cassie, subgroup 2G, said that she would, "...go over and make sure they're okay and help them up", regardless of the gender of her teammate. Most women agreed that they would ask the man or the woman teammate if they were okay. Some were not as willing as Cassie to help up the man as they were the woman. "I'd give them (man teammate) a hand if they needed it. I'm sure he'd want one of my male counterpart's hands other than mine but..." When asked why she felt this way, Kelsey, subgroup 2G, laughed, "I don't know... cause I'm a girl! I think they would think it was weird." Therefore, while verbally treating everyone with an injury the same, the non-verbal gesture varied among women based on their level of comfortability with the men on their team.

Verbal communication regarding an injury is strongly gendered, while non-verbal may be to a lesser extent. While the men and the women ask women if they are okay after sustaining an injury, the women are the only ones who continue to extend the question to men teammates. Men are more likely to ridicule, even if jokingly, another man for showing that he is injured. The non-verbal line may be less gendered, given that all men and women help up an injured woman teammate and all men and some women 
do not help up an injured man teammate. Given the rarity of injuries in co-recreational basketball games, this situation was not observed and therefore unable to be triangulated with interview responses.

\section{NEGOTIATING A PREDOMINANTLY MASCULINE ENVIRONMENT}

With basketball, and co-recreational intramural basketball in particular, being named as a predominantly masculine sport by both men and women interviewees and many situational communication styles proving as gendered, the second of this study's research questions of how players use these gendered communication styles as strategies to negotiate this masculine environment is indeed a relevant one. Men and women interviewees noted that the men players are not the ones who are making an effort to negotiate the permeating masculinity during games, but women must do so if they want to be taken seriously as an "asset" rather than a "requirement", to use Ellie's notion of the typical role of women on these teams.

Having verbal and non-verbal gendered communication styles at their will, women appear to have a variety of ways to let their men teammates know that they are there to play and not to be a body on the floor. Most women, however, neglect the use of verbal and resort to non-verbal gestures to get their point across. Only a couple women players mentioned the use of verbal messages when negotiating the predominantly masculine environment of co-recreational intramural basketball. Monica, subgroup 2G, said that when she is getting left out on the court, she will say something like, "You all (the men teammates) aren't involving us (the women teammates)" or "This 
isn't fun for us (the women teammates)." Even after a verbal comment is made by a woman player, Monica notes that nothing about the team dynamic changes until a man teammate, usually "one of the guys that's, like, more welcoming" has to say something as well. Monica claimed that a man teammate has to follow-up her comment by saying, "Hey, like, pass it to them (the women teammates). They're wide open."

With the lack of results that verbal attempts bring to women players, it is not surprising that they focus their efforts on non-verbal gestures in order to negotiate the masculinity in their choice of serious leisure. Many interviewees, both men and women, acknowledged that by doing certain things, a woman teammate can get herself noticed and perhaps that will lead to better treatment by her men teammates. Matthew, subgroup 1B, noted that to break the gender barriers they face, women players must "work hard on defense a lot and then, whenever they get the ball, they try to contribute." Chelsea, subgroup 2B, agreed with Matthew in his view of using good defense to make a statement, but went even further in saying that defense itself wasn't good enough; it had to be good defense against good women players: "...that's when it's your (a woman player's) turn to take, take charge... when the other team has good girls." Women players trying to stand out on defense, especially against women opponents with skill, was noticed during the observation of games, thus giving credibility to this tool used by women negotiating predominantly masculine environments.

Even after verbal or non-verbal efforts of women teammates, women interviewees, like Monica, claimed that men teammates did not include them in the 
offensive end of the game. Mason, subgroup 1G, agreed with those women as he stated, “...unfortunately, I think a lot of that (women's negotiating masculinity) is on the guys to, like, let her do that (show that she wants to be involved)." Thus, no matter the skill of the women teammates, the men are often charged for not including them as they do their men teammates; even the men themselves noticed, as proved by Mason, that they fail to include the women, even when they are making verbal or non-verbal attempts to be seen in this predominantly masculine environment. 


\section{CHAPTER 5: CONCLUSION}

With each theme, whether regarding serious leisure, multiple self identities, or gendered communication, there was often consistency within each gender. Using the gender groups, there are implications to be drawn for how men and women perceive co-recreational intramural basketball; thus, these implications should be discussed. After using gender groups to explain the overall serious leisure standpoint, the subgroups that were created by gender and skill level were also bonded by identity prioritization techniques within a predominantly masculine environment. Their likeness in these ways brought upon their initial grouping and also the classifications I later assigned them after seeing these similarities. Using these classifications will help explain their choices regarding athlete and gender identities. These subgroup classifications may not be applicable for explaining the presence of gendered communication, but this is also to be explored below. Finally, after a discussion on serious leisure, multiple self identities, and gendered communication, larger implications for research and society are specified. 


\section{THE LOSE-LOSE SITUATION IN A SERIOUS LEISURE SITUATION}

Barbara Carton (1999) made the claim that co-recreational athletics, high school wrestling in her case, were lose-lose situations for teenage boys; they could not beat or be beaten by a teenage girl. Those girl wrestlers that proved a threat to the boys were not seen to have had the same disadvantage. Girls could beat or be beaten by a boy and not be negatively affected as a boy would in either case. Moving into college, the case seems to have not changed for men, as they are still unable to win when competing with or against women opponents. Their women counterparts, on the other hand, have seen a shift in their relation to the lose-lose situation. Now, the lose-lose situation that Carton (1999) pitied boys for being in while in high school also extends to collegiate women co-recreational intramural basketball players.

Men players are at a fork in the road when playing with or against women players. Do they try harder to include her because she is "just a girl", which could include passing to her when they would rather take the shot themselves, allowing her to shoot instead of blocking her, etc., or try to treat her like "one of the guys", which could include not passing to her just because they want to take the shot themselves, blocking her, etc.? In the first instance, when a man teammate tries hard to include her, a woman teammate will argue that he is just "letting her play" because she is a woman; she will claim that she wishes he would respect her and treat her like he would any of his other teammates. If he does so, then, treat her as he would in the second circumstance, a woman may claim that he is "ignoring" her because she is a woman. 
Men, then, are indeed in a lose-lose situation because no matter how they treat their women teammates or opponents, they cannot win.

Knowing that some women like to be treated like "girls" and some like to be treated as "one of the guys" makes them aware that guys are in a tough spot when playing co-recreational intramural basketball. They also agree with men, regardless of their skill set, that women are not as skilled as men. Women, then, are presented with the same fork in the road as men, only with different paths marking each direction. Women could choose to play co-recreational intramural basketball and thus bring down the competition level of the game; or they could choose not to play and allow the men to play the game at their higher level of competition. Women, then, are in a lose-lose situation as well because if they choose to play, they are self-conscious of being worse than the men during every game. If they choose the alternative option, not to play, then their loss is simple: they do not get to participate in something they (are likely to) consider serious leisure.

Regardless of this lose-lose situation for both men and women, they have been and are still choosing to play. It is unclear as to whether their play is affected by their knowing of their inevitable disappointment in co-recreational intramural basketball. Perhaps this consciousness, though, plays into their choice in showing or hiding their athlete and gender identities, as well as choosing to prioritize one over the other. 


\section{EXPLAINING CHOICES REGARDING ATHLETE AND GENDER IDENTITIES}

\section{THE SUPERIORITY COMPLEX}

"That's how they (skilled men athletes) see all sports... They just have this superiority complex."

-Lisa, subgroup 2B.

The men in subgroup $1 \mathrm{G}$ were the best of the best in terms of skill set. All of them played basketball in high school, and many of them played on multiple intramural teams (both of the mixed and single sex variety). They felt empowered due to their being men and also being good, if not great, at basketball, which made them feel superior while on the court. They were alike not only in gender and skill, but also in their claim to have hid their athlete identity when playing co-recreational intramural basketball. They did so because they knew how talented of athletes they were, so they refrained from showing their total athleticism in order to avoid being called "ballhogs" or "show offs" by their women teammates; most men did not indicate they cared if other men thought they fell under these labels. Hiding their athlete identity is connected to the showing of their gender identity for their gender consciousness is the root reason for hiding their athlete identity. Being aware of playing with and against women prevented these men from playing to their fullest potential.

Given their hiding of the athlete and showing of the gender identities, it is not surprising that most, three of four, of the men in subgroup 1G claimed to prioritize their gender identity over that of their athlete. The co-recreational intramural basketball 
players that have this "superiority complex", or men players with skill, would rather not play as hard in order to include their women teammates and prevent them from feeling bad for not being as good as these talented men. The women teammates that they are "including" may have a different opinion on the men's efforts to restrain themselves and include them, but this is an interpretation of the reasoning behind the skilled men subgroup's identity prioritization.

\section{THE INFERIORITY COMPLEX}

“...you set your expectations and if someone doesn't meet your expectations, then you're disappointed, but if you set your expectations low, and then the result is low, then you really, like, can't be mad cause, like, that's what you expected."

-Tommy, subgroup 1B.

Subgroup 1B's men were the players on each team with less skill than the other men. Differing from the men in subgroup 1G, these men players showed their athlete identity. Perhaps they know they're not as good at basketball, so they have to try harder in order to look mediocre; this may allow them to match the toned-down to mediocre play of talented men players. Not only are they wanting to look as good as the skilled men, they also want to look better than the women players, regardless of the women's skills, to prevent feeling inferior to both men and women. Playing harder with and against women may seem contradictory to being able to show one's gender identity, but these men balance the showing of both identities by playing hard but also by being 
more "welcoming to the women", or passing to them more and not being too aggressive when playing against them.

Though showing athlete and gender identity, these men claimed to prioritize gender like the men in subgroup 1G. Men in subgroup 1B claimed to care more about women's feelings than feeling inferior to the better men or the women they are trying to appease. This is why they tried to pass more, as their trying to include the women was their way of showing their gender consciousness and care for their women teammates. The women they are claiming to include did agree to noticing the men's efforts; many women claimed that when included, it was by men of lesser skill.

\section{THE HANDCUFFED COMPLEX}

"...even if, like, we wanted to give it all we had, it's like there's nothing to do 'cause we're not being, like, involved." -Monica, subgroup 2G.

Women with more skill compiled subgroup 2G. Even with their skill, most of these women, four of six, hid their athlete identity while playing co-recreational basketball, but often not by choice. Skilled women were frustrated with the lack of opportunities they were presented with which prevented them from showing their athlete identity even if they wanted to. This being handcuffed to hiding their athlete identity almost forced them to show their gender identity because the hiding of their athlete identity felt tied to their gender, making them more gender conscious. Also, given that they were less likely to get the ball, they were looked upon as playing "girly" 
because they were taken out of potentially aggressive situations; there were exceptions, of course, where skilled women did take control when given the opportunity, but the point is that the opportunity was ever-present for men of all skill levels and not for skilled women.

Being forced to hide their athlete identity because of their gender identity made almost all, five of six, claim to have prioritized their athlete identity in co-recreational intramural basketball games. These skilled women wanted to show the men that were preventing them from showing their athleticism to the fullest extent that they were good, if not great, basketball players too. These women felt as though they were not only standing up for women basketball players, but making a statement for women as athletes in general, whenever they had a chance to do so.

\section{THE BODY COMPLEX}

"...honestly, I just got so used to not getting passes that I wouldn't... like, I stopped doing all that (trying to get open, calling for the ball, etc.) to get open and get the ball."

-Ellie, subgroup $2 \mathrm{G}$.

Women that did not have as much talent in basketball, subgroup 2B, claimed to show their athlete identity because they did not like being considered just "bodies" on the court. In order to fight that stigmatization, the women made every effort to show the men that they were better than they thought. Trying to show the men their athlete identity because of their gender naturally made them conscious of their gender identity 
as well. Whenever a woman with less skill would do something well, she would not only be proud of herself but also proud for women in general, knowing she had just helped make a statement to the men who assumed she wasn't good because she was "just a girl."

Like the women in subgroup $2 \mathrm{G}$, wanting to show that women can be good at basketball, or just sports in general for the women with less basketball skill, the women in subgroup 2B prioritized their athlete identity in this serious leisure environment. These women took advantage of the times when men with less skill would give them an opportunity to play aggressively on offense. Other teams also gave them opportunities to make their case when they had talented women on their teams; they took advantage of these by playing their best defense as they felt that this was a way to send a message as well.

\section{EXPLAINING GENDERED COMMUNICATION STYLES}

Whether having a superiority or inferiority complex or a handcuffed or body complex, men and women of different skill levels joined in gender groups to show differences in approaching a variety of situations verbally and/or non-verbally. Both skilled and unskilled men do not guard women as hard, get overly excited when women teammates do something well, yell at other men but remain silent toward women when a turnover is committed, and speak harshly toward men but caringly toward women when an injury is sustained. Women, regardless of skill level, oppose these communication styles by guarding women as hard as they guard men, getting less 
excited for women who do something well (although still more excited than for men who do something well), speaking with comfort to women but not at all to men who turn the ball over, and caring for men and women if one should get injured during a game.

The explanation for these gendered communication styles may link to their awareness of the lose-lose situation. Men may be going easier on, cheering for, forgiving, and acting with care to women as they choose which path of the fork they are going to go down. To explain the difference in women's behavior, whether different verbally or non-verbally, it may be that they are torn between showing or hiding their athlete or gender identity in each situation. When guarding men tightly, they are showing their athlete identity; when getting less excited for women, they are again trying to keep their athlete identity at the forefront; when speaking with comfort to women, whether after a turnover or an injury, they are suppressing their urge to prioritize their athlete identity by addressing that of their gender. Whether men or women are making their lose-lose decision or just acting on their choice to show or hide their athlete or gender identities, there are differences in communication style; these are just two possible explanations for why they exist.

\section{LARGER IMPLICATIONS FOR RESEARCH AND SOCIETY}

This study supports, refines, and refutes pieces of past research in the areas of serious leisure, multiple self identities, and gendered communication in the context of co-recreational intramural basketball. Additionally, perhaps the findings of this study 
affect more than just the players in co-recreational basketball leagues, but all players entering mixed sex environments, as well as the institutions that offer these activities. Addressing both past literature and those that are affected in this context provides larger implications for academic research and even society as a whole.

The findings of this study support that of previous serious leisure research. Most of the participants in this study claimed that co-recreational intramural basketball was an activity of serious leisure for them. After doing so, I found that those who did make this claim fit the description of Stebbins $(2001,2010)$ when discussing serious leisure enthusiasts. Even more, the theory that the higher level on the RST a player lies, the more likely he or she is to consider an activity serious leisure was supported. Many of the players interviewed were technique specialists or technique-setting specialists. Even those with less skill were more likely to be generalists (as mentioned, those who were not highly skilled still considered intramural sports as a whole serious leisure). Thus, the higher level on the RST did equate to the consideration of co-recreational intramural basketball as serious leisure, or at the very least, intramurals as a whole as such.

This connects to the supporting of past identity literature. Those that considered co-recreational intramural basketball as serious leisure and were at a higher level on the RST also considered themselves to be athletes. Thus, the idea that Stebbins (2010) presented of a serious leisure enthusiast creating or maintaining or changing a strong identity with that leisure activity was supported. In addition to supporting Stebbins' (2010) identity literature, this study supported and refined that of Kaufman and Feldman (2004), Williams (2000), and Jones and McEwan (2000). Kaufman and Feldman 
(2004) agreed that identities are created or maintained or changed through interaction of college students, while Williams (2000) took it in a different direction in that this interaction occurred among individuals in leisure situations. This study proved that interaction among college students in a leisure environment engaged that creation or maintenance or change in identities. Though more of a big picture notion, Jones and McEwan (2000) claimed that individuals can have multiple identities at one time. This study supports that idea but refines it in that while individuals may have more than one at a time, they can prioritize those identities to where they are only conscious of one of the multiple identities, especially if the situation is one of fast pace.

The final area of interest that this study addressed was that of gendered communication. This study refuted the work of yet supported the suggestions from Sullivan (2004). Sullivan (2004) claimed that gendered communication differences did not exist in the sports of volleyball in soccer. In finding some situational differences in gendered communication, it would seem that this study would refute those previous findings. Sullivan (2004), however, did acknowledge that perhaps the findings in his research could be different than what would be found in other sports, particularly those of a more predominantly masculine environment like basketball. Therefore, while this study refutes Sullivan's (2004) findings, it supports his suggestion as to where future research might have done so. In finding situational gendered communication differences, this study refines previous work that also acknowledged those dissimilarities in that it adds that perhaps leisure activities are another area where differences exist (Dindia and Allen 1992; Duck and Wright 1993; Aries 1996; Timmers, 
Fischer, and Manstead 1998; Fehrs, Baldwin, Collins, Patterson, and Benedict 1999;

Kinney, Smith, and Donzella 2001).

After looking at the implications for research, it is also important to look at how this study impacts society and those within it. The group most directly affected by the findings of this study are the players. Perhaps in looking at how this study's findings affect them, larger conclusions can be drawn about how they also should influence the institutions that offer these leisure activities.

If men and women are encountering a no-win situation by playing corecreational intramural basketball, why do they still play? For talented men and women, the answer is often that they just want another chance to play. For men and women with less skill, they want to have fun doing something active with their friends. But if both genders are at a disadvantage for playing, what is the solution? Should corecreational intramural leagues be eliminated? Is there a way to prevent these leagues from being a lose-lose situation for men and women?

When discussing co-recreational intramural sports with Willow, subgroup $2 B$, she insisted that the solution to preventing disappointment for men and women playing sports together starts when they are young:

"It's really important to play with men and women when you're young. When you separate that (young boys and girls in sports leagues), people learn, like, 'This is what girls do and this is what boys do and this is how you fit in the girl's box and this is how you fit in the boy's box', I think that makes people look at genders differently, like, 'Oh. That's a girl. She did a really good job. That was so impressive.' But if a guy did it, you'd be like, 'Oh. That was pretty normal.' 
So I think... I just think it's important to play with girls and with boys."

Thus, perhaps the point of this study is not only to see how men and women prioritize their multiple identities and engage in gendered communication, but also to send a message to society to prevent this serious leisure activity from continuing to be predominantly masculine and enforcing a lose-lose situation for men and women. Thus, the message to the institutions offering these activities should be to start corecreational leagues when girls and boys are young so that they may develop serious leisure interests in a mixed sex environment. Perhaps when they grow older, their prioritization of multiple self identities and gendered communication styles will not be connected to an underlying lose-lose situation because by that time, men and women will have grown used to playing together and supporting one another in a multitude of activities regardless of gender and skill level. 


\section{REFERENCES}

"University Rewards Students for Participating in Co-curricular Events." 2004. Academic Leader 20 (3): 2.

Adler, Patricia A., and Peter Adler. 1987. Membership Roles in Field Research, vol. 6. Newbury Park: SAGE Publications.

Anderson, Eric. 2008. "'I Used to Think Women Were Weak': Orthodox Masculinity, Gender Segregation, and Sport." Sociological Forum 23 (2): 257-280.

Anderson, Eric, Rory Magrath, and Rachel Bullingham. 2016. Out in Sport: The Experiences of Openly Gay and Lesbian Athletes in Competitive Sport. London: Routledge.

Aries, E. 1987. "Gender and Communication" in Sex and Gender, P. Shaver and C. Hendrick, eds. Pp. 149-176. Newbury Park, CA: SAGE Publications.

Aries, E. 1996. Men and Women in Interaction: Reconsidering the Differences. New York: Oxford University Press.

Artinger, Lori, Lisa Clapham, Carla Hunt, Matthew Meigs, Nadia Milord, Bryan Sampson, and Scott A. Forrester. 2006. "The Social Benefits of Intramural Sports." NASPA Journal 43 (1): 69-86.

Auster, Carol J. 2008. "The Effect of Cohort on Women's Sport Participation: An Intergenerational Study of Collegiate Women Ice Hockey Players." Journal of Leisure Research 40 (2): 312.

Babbie, Earl. 2013. The Practice of Social Research, $14^{\text {th }}$ ed. Australia: Cengage Learning.

Bertozzi, Elena. 2008. "'You Play Like a Girl!' Cross-Gender Competition and the Uneven Playing Field." Convergence 14 (4): 473-487.

Birrell, Susan. 2000. "Feminist Theories for Sport." Handbook of Sports Studies 29: 6176.

Blumer, Herbert. 1986. Symbolic Interactionism: Perspective and Method. University of California Press.

Bocarro, J., M. Kanters, and J. Casper. 2006. "Research Update: Leisure for Life." Parks \& Recreation 41 (6): 22-27. 
Bricker, Kelly S. and Deborah L. Kerstetter. 2000. "Level of Specialization and Place Attachment: An Exploratory Study of Whitewater Recreationists." Leisure Sciences 22 (4): 233-257.

Bryan, Hobson. 1977. "Leisure Value Systems and Recreational Specialization: The Case of Trout Fishermen." Journal of Leisure Research 9 (3): 174.

Canary, D. J. and K. S. Hause. 1993. "Is There Any Reason to Research Sex Differences in Communication?" Communication Quarterly 41: 129-144.

Carton, Barbara. 1999. "When Girls Wrestle, The Boys They Face Can't Win for Losing." Wall Street Journal, January 19. Retrieved April 15 th 2016.

Chand, V. 2005. "Communication Strategies for Athletes." Current Anthropology 46 (4): 499-500.

Charmaz, Kathy. 2014. Constructing Grounded Theory. New York, New York: SAGE Publications.

Charon, Joel M. 2007. Symbolic Interactionism, $9^{\text {th }}$ ed. New Jersey: Pearson.

Chatham-Carpenter, A. and V. DeFrancisco. 1998. "Women Construct Self-Esteem in their Own Terms: A Feminist Qualitative Study." Feminism \& Psychology 8: 467489.

Chen, S., S. Snyder, and M. Magner. 2010. "The Effects of Sport Participation on Student-Athletes' and Non-Athlete Students' Social Life and Identity." Journal of Issues in Intercollegiate Athletics 3 (1): 176-193.

Clapp, Brian. 2016. "Inside the World of Corporate Sponsorships in Sport." Work in Sports.

Connell, Raewyn and James W. Messerschmidt. 2005. "Hegemonic Masculinity: Rethinking the Concept." Gender and Society 19 (6): 829-859.

Connell, Raewyn. 1995. Masculinities, $2^{\text {nd }}$ ed. Cambridge: Polity Press.

Crawford, Duane W., and Geoffrey Godbey. 1987. "Reconceptualizing Barriers to Family Leisure." Leisure Sciences 9 (2): 119-127.

Crowston, K. and E. Kammeres. 1998. "Communicative Style and Gender Differences in Computer-Mediated Communications" in Cyberghetto or Cybertopia, B. Ebo, ed. Pp. 185-202. Wesport, CT: Praeger.

David, Deborah Sarah and Robert Brannon, eds. 1976. The Forty-Nine Percent Majority: The Male Sex Role. New York, New York: Random House.

Deaner, Robert O., David C. Geary, David A. Puts, Sandra A. Ham, Judy Kruger, Elizabeth Fles, Bo Winegard, and Terry Grandis. 2012. "A Sex Difference in the Predisposition for Physical Competition: Males Play Sports Much More Than Females Even in the Contemporary U.S." PLOS ONE 7 (11): 1-15. 
Dindia, K. and M. Allen. 1992. "Sex Differences in Self-Disclosure: A Meta-Analysis." Psychological Bulletin 122: 106-124.

Duck, S. and P. H. Wright. 1993. "Reexamining Gender Differences in Friendship: A Close Look at Two Kinds of Data." Sex Roles 28: 709-727.

Falls, Dominique and Brian Wilson. 2012. "'Reflexive Modernity' and the Transition Experiences of University Athletes." International Review for the Sociology of Sport 48 (5): 572-593.

Fehrs, B., M. Baldwin, L. Collins, S. Patterson, and R. Benedict. 1999. "Anger in Close Relationship: An Interpersonal Script Analysis." Personality and Social Psychology Bulletin 25: 299-312.

Fields, Sarah K. 2007. "Intramural and Club Sports: The Impact of Title IX." JC \& UL 33: 521.

Gagné, Patricia and Richard Tewksbury. 1996. “No 'Man's' Land: Transgenderism and the Stigma of the Feminine Man." Advances in Gender Research 1: 115-155.

Gibbons, Judith L. and Brien K. Ashdown. 2006. "Emerging Adulthood: The Dawning of a New Age." American Psychological Association 51 (35).

Goffman, Erving. 1959. The Presentation of Self in Everyday Life. Garden City, NY: Anchor.

Golafshani, Nahid. 2003. "Understanding Reliability and Validity in Qualitative Research." The Qualitative Report 8 (4): 597-606.

Great Schools Partnership. 2013. "Co-Curricular Definition." The Glossary of Education Reform.

Grubb, M. V. and T. Billiot. 2010. "Women Sportscasters: Navigating a Masculine Domain." Journal of Gender Studies 19 (1): 87-93.

Guerrero, L., S. Jones, and R. Boburka. 2006. "Sex Differences in Emotional Communication" in Sex Differences and Similarities in Communication, K. Dindia and D. Canary, eds. Pp. 242-261. Mahwah, MJ: Erlbaum.

Guest, Greg, Emily E. Namey, Marilyn L. Mitchell. 2013. Collecting Qualitative Data: A Field Manual for Applied Research. Los Angeles: SAGE Publications.

Haggard, Lois M. and Daniel R. Williams. 1992. "Identity Affirmation through Leisure Activities: Leisure Symbols of the Self." Journal of Leisure Research 24 (1): 1-18.

Hall, D. and L. Langellier. 1988. "Storytelling Strategies in Mother-Daughter Communication" in Women Communicating: Studies of Women's Talk, B. Bate and A. Taylor, eds. Pp. 107-126. Norword, NJ: Ablex.

Hall, J. A. 1998. "How Big are Nonverbal Sex Differences? The Case of Smiling and Sensitivity to Nonverbal Cues" in Sex Differences and Similarities in 
Communication, D. J. Canary and K. Dindia, eds. Pp. 155-178. Mahwah, NJ: Erlbaum.

Hamilton, J. 2016. “Don't Play Travel Ball: Stay in the Rec League." Journal for Biblical Manhood \& Womanhood 21 (1): 7-11.

Hanson, Sandra L. and Rebecca S. Kraus. 1999. "Women in Male Domains: Sport and Science." Sociology of Sport Journal 16: 92-110.

Hardin, Marie. 2009. "The Influence of Gender-Role Socialization, Media Use and Sports Participation on Perceptions of Gender-Appropriate Sports." Journal of Sport Behavior 32 (2): 207-226.

Hekma, Gert. 1998. "'As long as they don't make an issue of it . . .: Gay men and lesbians in organized sports in the Netherlands." Journal of Homosexuality 35 (1): 1-23.

Herbert, James R., Yunsheng Ma, Lynn Clemow, Ira S. Ockene, Gordon Saperia, Edward J. Stanek, Philip A. Merriam, and Judith K. Ockene. 1997. "Gender Differences in Social Desirability and Social Approval Bias in Dietary Self-Report." American Journal of Epidemiology 146 (12): 1046-1055.

Hudson, B. 2001. African American Female Speech Communities: Varieties of Talk. Westport, CT: Bergin \& Garvey/Greenwood Press.

Hurtado, Aida and Mrinal Sinha. 2010. Doing Gender Diversity: Readings in Theory and Real-World Experience, Rebecca F. Plante and Lis M. Maurer, eds. Boulder: Westview Press.

Hyatt, Ronald. 1977. Intramu Sports: Organization and Administration. Saint Louis, MO: Mosby.

Institutional Research at the University of Louisville. 2012. "Common Data Set 20112012." Retrieved August 29th 2016.

Institutional Research at the University of Louisville. 2016. "Common Data Set 20152016." Retrieved September $1^{\text {st }}, 2016$.

Jakupcak, Matthew, David Lisak, Lizabeth Roemer. 2002. "The Role of Masculine Ideology and Masculine Gender Role Stress in Men's Perpetration of Relationship Violence." Psychology of Men and Masculinity 3 (2): 97.

Johnson, F. 1996. "Friendships Among Women: Closeness in Dialogue" in Gendered Relationships: A Reader, Julia T. Wood, ed. Pp. 79-94. Mountain View, CA: Mayfield.

Jones, Susan R. and Marylu K. McEwan. 2000. "A Conceptual Model of Multiple Dimensions of Identity." Journal of College Student Development 41 (4): 405. 
Jun, Jinhee and Gerard T. Kyle. 2012. "Gender Identity, Leisure Identity, and Leisure Participation." Journal of Leisure Research 44 (3): 353-378.

Jun, Jinhee, Gerard T. Kyle, Alan Grafe, and Robert Manning. 2015. "An Identity-Based Conceptualization of Recreation Specialization." Journal of Leisure Research 47 (4): 425-443.

Jurczyk, K. 1998. "Time in Women's Everyday Lives: Between Self-Determination and Conflicting Demands." Time and Society 7 (2): 283-308.

Kaufman, Peter and Kenneth A. Feldman. 2004. "Forming Identities in College: A Sociological Approach." Research in Higher Education 45 (5): 463-496.

Kimmel, Michael. 2008. Guyland: The Perilous World Where Boys Become Men. New York: Harper.

Kimmel, Michael. 2013. The Gendered Society, $5^{\text {th }}$ ed. New York: Oxford University Press.

Kinney, T. A., B. A. Smith, and B. Donzella. 2001. "The Influence of Sex, Gender, SelfDiscrepancies, and Self-Awareness on Anger and Verbal Aggressiveness among U.S. College Students." Journal of Social Psychology 141: 245-276.

Kneidinger, L. M., T. L. Maple, and S. A. Tross. 2001. "Touching Behavior in Sport: Functional Components, Analysis of Sex Differences, and Ethological Considerations." Journal of Nonverbal Behavior 25: 43-62.

Kohlberg, Lawrence. 1966. "A Cognitive-Developmental Analysis of Children's Sex-Role Concepts and Attitudes." The Development of Sex Differences.

Krane, Vikki, Precilla YL Choi, Shannon M. Baird, Christine M. Aimar, and Kerrie J. Kauer. 2004. "Living the Paradox: Female Athletes Negotiate Femininity and Muscularity." Sex Roles 50 (5/6): 315-329.

Kuh, G. D., J. H. Schuh, and E. J. Whitt. 1991. "Some Good News about Campus Life." Change 23 (5): 48.

Leaper, C. and M. Ayers. 2007. “A Meta-Analytic Review of Gender Variations in Adults' Language Use: Talkativeness, Affirmative Speech, and Assertive Speech." Personality \& Social Psychology Review 11: 328-363.

Liechty, Toni, Patti A. Freeman, and Ramon B. Zabriske. 2006. "Body Image and Beliefs about Appearance: Constraints on the Leisure of College-Age and Middle-Age Women." Leisure Sciences 28: 311-330.

Malcolm, Nancy L. 2006. "'Shaking It Off' and 'Toughing It Out': Socialization to Pain and Injury in Girls' Softball." Journal of Contemporary Ethnography 35 (5): 495-525.

McFarlane, Bonita L. 2004. "Recreation Specialization and Site Choice among VehicleBased Campers." Leisure Sciences 26 (3): 309-322. 
McIntyre, N. and J.J. Pigram. 1992. "Recreation Specialization Reexamined: The Case of Vehicle-Based Campers." Leisure Sciences 14 (1): 3-15.

Messner, Michael. 2012. Sport in Contemporary Society: An Anthology, $9^{\text {th }}$ ed. D. Stanley Eitzen, ed. Boulder: Paradigm Publishers.

Milton, Paul Rohe. 2008. "Collegiate Recreational Sports: A Historical Perspective." Journal of Research in Health, Physical Education, Recreation, Sport \& Dance 3 (1): 78-83.

Mulac, A. 2006. "The Gender-Linked Language Effect: Do Language Differences Really Make a Difference?" in Sex Differences and Similarities in Communication, K. Dindia and D. Canary, eds. Pp. 219-239. Mahwah, NJ: Erlbaum.

Murphy, B. and T. Zorn. 1996. "Gendered Interaction in Professional Relationships" in Gendered Relationships: A Reader, Julia T. Wood, ed. Pp. 213-232. Mountain View, CA: May Field.

NCAA. 2016. "Criteria for Emerging Sports."

$\mathrm{Ng}$, Wilson and Elayne Coakes. 2013. Business Research: Enjoy Creating, Developing and Writing Your Business Project. London: Kogan Page Publishers.

NIRSA. 2015. "About NIRSA."

Peterson, Justin, personal interview. 2016. Office of Intramural Recreational Sports, University of Louisville.

Preja, C. A. 2013. "Verbal and Non-Verbal Communication in Sports Culture." Palestrica of the Third Millennium Civilization \& Sport 14 (3): 239-243.

Riemer, B.A., and D. L. Feltz. 1997. "Cheering on Women and Girls in Sports: Using Title IX to Fight Gender Role Oppression." Harvard Law Review 110 (7): 1627-1645.

Rubin, Herbert J. and Irene S. Rubin. 2012. Qualitative Interviewing: The Art of Hearing Data, $3^{\text {rd }}$ ed. Los Angeles: SAGE Publications.

Ruddell, Jennifer L. and Kimberly J. Shinew. 2006. "The Socialization Process for Women with Physical Disabilities: The Impact of Agents and Agencies in the Introduction to an Elite Sport." Journal of Leisure Research 38 (3): 421-444.

Ryle, Robyn. 2012. Questioning Gender: A Sociological Exploration. Los Angeles: SAGE Publications.

Schippers, Mimi. 2007. "Recovering the Feminine Other: Masculinity, Femininity, and Gender Hegemony." Theory and Society 36 (1): 85-102.

Scott, David and C. Scott Shafer. 2001. "Recreational Specialization: A Critical Look at the Construct." Journal of Leisure Research 33 (3): 319-343. 
Shaw, Susan M., Douglas A. Kleiber, and Linda L. Caldwell. 1995. "Leisure and Identity Formation in Male and Female Adolescents: A Preliminary Examination." Journal of Leisure Research 27 (3): 245.

Smiler, Andrew P. "Conforming to Masculine Norms: Evidence for Validity among Adult Men and Women." Sex Roles 54 (11-12): 767-775.

Son, J. S., D. L. Kerstetter, and A. J. Mowen. 2008. "Do Age and Gender Matter in the Constraint Negotiation of Physically Active Leisure?" Journal of Leisure Research 40: 267-289.

Stebbins, Robert A. 2001. "Serious Leisure." Society 53-57.

Stebbins, Robert A. 2005. "Choice and Experiential Definitions of Leisure." Leisure Sciences 27 (4): 349-352.

Stebbins, Robert A. 2008. "Right Leisure: Serious, Casual, or Project-Based?" NeuroRehabilitation 23: 335-341.

Stebbins, Robert A. 2010. "Addiction to Leisure Activities: Is it Possible?" Leisure Reflections Newsletter 24: 20-22.

Stephens, Dawn E. 2004. "Moral Atmosphere and Aggression in Collegiate Intramural Sport." International Sports Journal 65-75.

Stevenson, S. J., M. R. Lochbaum, and G. S. Lowe. 2007. "Examining the Social-cognitive Model of Motivation: The Importance of Understanding Leisure Time Motivation." Journal of Sport \& Exercise Psychology 29: 204-205.

Stewart, Ralph E. 1973. "Brief History of the Intramural Movement." Physical Educator 30 (1): 26.

Stokoe, Elizabeth H. "Doing Gender, Doing Categorization: Recent Development in Language and Gender Research." International Sociolinguistics 2 (1): 1-12.

Sullivan, P. J. and D. L. Feltz. 2003. "The Preliminary Development of the Scale for Effective Communication in Team Sports (SECTS)." Journal of Applied Social Psychology 33: 1693-1715.

Sullivan, Philip. 2004. "Communication Differences between Male and Female Team Sport Athletes." Communication Reports 17 (2): 121-127.

Tannen, Deborah. 1991. You Just Don't Understand: Women and Men in Conversation. London: Virago.

Taylor, S. 2002. The Tending Instinct: How Nurturing is Essential for Who We are and How We Live. New York: Times Books.

Tenhouse, Amy M. 2008. "College Extracurricular Activities- Impact on Students, Types of Extracurricular Activities." Organizations, Involvement, Development, and University. 
Timmers, M., A. H. Fischer, and A. S. Manstead. 1998. "Gender Differences in Motives for Regulating Emotions." Personality and Social Psychology Bulletin 24: 974-985.

Walker, N. A. and M. L. Sartore-Baldwin. 2013. "Hegemonic Masculinity and the Institutionalized Bias toward Women in Men's Collegiate Basketball: What do Men Think?" Journal of Sport Management 2 (4): 303-315.

Wellman, J.D., Joseph W. Roggenbuck, and Alan C. Smith. 1982. "Recreation Specialization and Norms of Depreciative Behavior among Canoeists." Journal of Leisure Sciences 14 (4): 323.

West, Candace and Don H. Zimmerman. 2010. "Gender Diversity and the Binary" in Doing Gender Diversity: Readings in Theory and Real-World Experience, Rebecca F. Plante and Lis M. Maurer, eds. Boulder, Colorado: Westview Press.

Williams, Daniel R. 2002. "Leisure Identities, Globalization, and the Politics of Place." Journal of Leisure Research 34 (4): 351.

Wood, Julia T. 2013. Gendered Lives, $10^{\text {th }}$ ed. Boston, Massachusetts: Cengage Learning.

Wood, W., P. Christensen, M. Hebel, and H. Rothgerber. 1997. "Conformity to Sex-Typed Norms, Affect, and the Self-Concept." Journal of Personality and Social Psychology 73: 523-535.

World of Sports Science. 2016. "Recreational Sports."

Zapico, B., C. Tuero, J. Espartero, and R. González-Boto. 2014. "The Socialization Process and Gender Inequality in School Sports." Science and Sports 29: S20. 


\section{APPENDICES}

\section{APPENDIX 1. INTERVIEW GUIDE}

My name is Megan Robinson, and I am a Master's student in the sociology department at the University of Louisville. I have participated in intramural basketball for five years, with one of those years being at UofL. My research is on co-recreational intramural basketball and gendered communication. This interview will last anywhere between 35 and 60 minutes and will be audio recorded.

1. Tell me about your involvement with intramural basketball at the University of Louisville.

2. Why did you initially decide to participate in intramural basketball at UofL? In co-recreational basketball, specifically?

i. (Probe about socialization.)

3. Why did you decide to participate in co-recreational basketball, specifically?

4. How would you feel if you were no longer able to play co-recreational intramural basketball?

5. Given your participation, do you consider yourself an athlete? Explain why you feel this way.

The following questions pertain specifically to your co-recreational basketball experience.

6. Tell me about how you demonstrate your athlete identity while playing corecreational intramural basketball.

i. (Probe about how your athlete identity may shape your gendered communication. Get stories.)

7. Tell me about how you demonstrate your gender identity.

i. (Probe about how your gender identity may shape your gendered communication. Get stories.)

8. Are there any other identities that are important to you? Can you describe them?

a. Rank all identities being described.

9. How might your participation have changed your identities and/or their importance? 
10. Describe your thoughts and/or feelings when guarding a member of the same sex.

11. Imagine a teammate of the same sex hits a three pointer. What do you say to him/her? How do you act?

12. Imagine a teammate of the same sex turns the ball over, allowing the other team to score. What do you say to him/her? How do you act?

13. Imagine a teammate of the same sex falls down injured. What do you say to him/her? How do you act?

14. Describe your thoughts and/or feelings when guarding a member of the opposite sex.

15. Imagine a teammate of the opposite sex hits a three pointer. What do you say to him/her? How do you act?

16. Imagine a teammate of the opposite sex turns the ball over, allowing the other team to score. What do you say to him/her? How do you act?

17. Imagine a teammate of the opposite sex falls down injured. What do you say to him/her? How do you act?

The following questions pertain to demographic information.

18. What is your gender identification?

19. What is your age?

20. What is your race/ethnicity?

21. How long have you played co-recreational intramural basketball at the University of Louisville?

22. Are you a full or part-time student?

23. Are you a full or part-time worker?

24. Did you play organized basketball in high school? 


\section{APPENDIX 2. RECRUITMENT EMAIL}

Hello team captain of a co-recreational intramural basketball team at UofL,

My name is Megan Robinson, and I am a Master's student in the sociology department at the University of Louisville. I have participated in intramural basketball for five years, with one of those years being at UofL.

I am contacting you because I am asking for your voluntary participation in a 35-60 minute interview for my thesis on co-recreational intramural basketball and the processes within the league.

The purpose of this study is to explore how intramural sport participants manage their multiple identities when playing with or against those of the same or opposite sex. The study will also research how recreational sport participants use gendered communication strategies to negotiate predominantly masculine leisure environments or activities, e.g., co-recreational basketball leagues.

Please contact me at megan.robinson.1@louisville.edu or (765) 366-4287 if you are willing to participate. I am looking to interview 20-30 participants, so your willingness to participate would be greatly appreciated. Additionally, please forward this email to your co-recreational intramural league teammates and ask them to contact me as well if they are willing to participate.

A final note, as I may need to get in touch with you at a later date, please contact me via email or text with your first and last name, your email, and your phone number.

Thank you,

Megan Robinson

Department of Sociology 
APPENDIX 3. CONSENT FORM

\section{Subject Informed Consent Document \\ Identity Prioritization and Gendered Communication In Co-Recreational Basketball}

Sponsor assigned number:

Grant assigned number:

Industry Contracts number:

Sponsor(s) name \& address:

Investigator(s) name \& address: Dr. Mark Austin, Dept. of Sociology Room 123

Megan Robinson, Dept. of Sociology Room 113

Site(s) where study is to be conducted: University of Louisville

Phone number for subjects to call for questions: (502) 852-8044

\section{Introduction and Background Information}

You are invited to participate in a research study. The study is being conducted by Megan Robinson, B.A. The study is sponsored by the University of Louisville, Department of Sociology. The study will take place at the University of Louisville. Approximately twenty to thirty subjects will be invited to participate.

\section{Purpose}

The purpose of this study is to explore how intramural sport participants manage their multiple identities when playing with or against those of the same or opposite sex. The study will also research how recreational sport participants use gendered communication strategies to negotiate predominantly masculine leisure environments or activities, e.g., co-recreational basketball leagues.

\section{Procedures}

In this study, you will be asked to participate in an interview of approximately thirty-five to sixty minutes that will ask about your intramural basketball experience and demographic information. The total study length will be one school year. You may decline to answer any question that may make you uncomfortable. 


\section{Potential Risks}

There are no foreseeable risks.

\section{Benefits}

The possible benefits of this study include contributing to the academic advancement of research on co-recreational intramural basketball and gendered communication in sport. The information collected may not benefit you directly. The information learned in this study may be helpful to others.

\section{Compensation}

You will not be compensated for your time, inconvenience, or expenses while you are in this study.

\section{Confidentiality}

Total privacy cannot be guaranteed. Your privacy will be protected to the extent permitted by law. If the results from this study are published, your name will not be made public. While unlikely, the following may look at the study records:

The University of Louisville Institutional Review Board and Human Subjects Protection Program Office, Office for Human Research Protections (OHRP).

\section{Conflict of Interest}

There is no conflict of interest in this study.

\section{Security}

Your information will be kept private because documents, though none will contain your name, will be kept in a locked box in the office of the second investigator, Megan Robinson. The audio files will be kept on an encrypted flash drive. When not in use, the audio file will also be kept in the locked box in the same office.

\section{Voluntary Participation}

Taking part in this study is voluntary. You may choose not to take part at all. If you decide to be in this study you may stop taking part at any time. If you decide not to be in this study or if you stop taking part at any time, you will not lose any benefits for which you may qualify. 


\section{Contact Persons, Research Subject's Rights, Questions, Concerns, and Complaints}

If you have any concerns or complaints about the study or the study staff, you have three options.

You may contact the principal investigator at (502) 852-8044.

If you have any questions about your rights as a study subject, questions, concerns or complaints, you may call the Human Subjects Protection Program Office (HSPPO) (502) 852-5188. You may discuss any questions about your rights as a subject, in secret, with a member of the Institutional Review Board (IRB) or the HSPPO staff. The IRB is an independent committee composed of members of the University community, staff of the institutions, as well as lay members of the community not connected with these institutions. The IRB has reviewed this study.

If you want to speak to a person outside the University, you may call 1 877-852-1167. You will be given the chance to talk about any questions, concerns or complaints in secret. This is a 24 hour hot line answered by people who do not work at the University of Louisville. 


\section{Acknowledgment and Signatures}

This informed consent document is not a contract. This document tells you what will happen during the study if you choose to take part. Your signature indicates that this study has been explained to you, that your questions have been answered, and that you agree to take part in the study. You are not giving up any legal rights to which you are entitled by signing this informed consent document. You will be given a copy of this consent form to keep for your records.

Subject Name (Please Print)

Printed Name of Legal Representative (if applicable)

Relationship of Legal Representative to Subject

Printed Name of Person

Explaining Consent Form
Signature of Subject

Date Signed

Signature of Legal Representative Date Signed
Signature of Person Explaining Consent Form (if other than the Investigator)

Printed Name of Investigator

List of Investigators:

Phone Numbers:

Megan Robinson

(502) 852-8044 


\title{
CURRICULUM VITAE
}

\author{
Megan Robinson
}

765.366.4287•robinson0892@gmail.com

\section{Education}

University of Louisville, Expected MA

- Applied Sociology
Louisville, KY

Fall 2015-Current

Hanover, IN

Fall 2011-Spring 2015

- GPA: 3.8 (Overall), 4.0 (Major)

- Major: Sociology, Concentration: Business, Minor: Mathematics

- Study Abroad: Taipei, Taiwan

- Received the Eli Lilly Scholarship: a four year, full tuition scholarship given to one student per county in Indiana.

\section{Research Interests}

- Sociology of Leisure

- Sociology of Gender

- Sociology of Education

\section{Academic Professional Experience}

Graduate Teaching Assistant

- Sociology 201: Introduction to Sociology
Louisville, KY

Fall 2016-Current

- Teach discussion sections of 30 students twice a week.

- Orchestrate one online class.

- Grade papers of 60 students plus online students on a weekly basis for SOC 201 professor.

- Hold office hours twice a week to provide tutoring opportunities if needed. 
- Sociology 405/605: Voluntarism

- Track grades for 15 undergraduate and graduate students.

- Sociology 301: Social Statistics

Fall 2015-Spring 2016

O Tutored students in five classes, including one online class.

- Held office hours daily in order to assist students with statistics questions.

- Corresponded with professors and students about course material.

\section{Research Projects}

- "The Lose-Lose Situation: Identity Prioritization and Gendered Communication in CoRecreational Intramural Basketball"

- Master's Thesis, University of Louisville, Spring 2016-Spring 2017

- "Impression Management in Intramural Basketball"

○ Senior Thesis, Hanover College, Spring 2015

\section{Presentations}

- "The Lose-Lose Situation: Identity Prioritization and Gendered Communication in CoRecreational Intramural Basketball"

- North Central Sociological Association Annual Conference, Indianapolis, March 31, 2017

- Graduate Student Regional Research Conference, University of Louisville, March 25, 2017

- "Impression Management in Intramural Basketball"

○ Undergraduate Research Conference, Butler University, April 10, 2015

\section{Guest Lectures}

- "Finding and Supporting a Theme"

- Qualitative Methods, University of Louisville, April 6, 2017

- "History of the Family"

- Sociology of Families, University of Louisville, January 19, 2017 
- Gained knowledge, skills, and experience with the scholarship of teaching and learning in higher education.

- Acquired practical strategies, tools, and resources.

- Interacted with faculty mentors and graduate students from across the university to network and gain a broad perspective of teaching and learning in higher education.

- Prepared for being a graduate teaching assistant and for the future academic job market.

\section{PLAN Workshops (Professional development, Life skills, Academic development, and} Networking) Lo uisville, KY

- Enriched professionally through:
O Power Literature Searching.
- Dissertation and Thesis Information Session.
- Reading and Responding to Graduate-Level Scholarship.
- The Academic Job Search.
○ Difference Between CV and Resume.

\section{Honors and Awards}

- Outstanding Graduate Student of the Month

- Henry C. Long for Scholarship and General Excellence

- Robert R. and Clara J. Beach Award in Sociology

- Dean's List honoree eight semesters

- Global Scholar

- Parker Scholar

- Gamma Sigma Pi Junior and Senior Honor Society

- Mortar Board Honor Society

- Alpha Lambda Delta Honor Society

- EndNote

- Atlas.ti 


\section{Extra-Curricular Activities}

\section{External Vice President of the Graduate Student Council}

- Elected by a majority of representatives of over 5,000
Louisville, KY

Spring 2016-Current

graduate students to the position of External Vice President in order to preside over Council meetings and act as the face of the Council to the public.

- Planning, with assistance from a committee, the largest events that the Council hosts, including a Research Conference, Three Minute Thesis competition, and a Halloween party.

\section{President of the Sociology Graduate Student Association}

- Elected by a majority of around 30 graduate students in the
Louisville, KY

Fall 2016-Current Sociology department to the position of President in order to preside over Association meetings and act as the face of the department to the public.

- Planning department wide events to increase comradery among graduate faculty and students.

- Organizing research bootcamps to encourage support in graduate students' research among peers.

\section{Student Body President}

Hanover, IN

- Elected by a majority of over 500 peers to the position of Student Body President in order to preside over Senate meetings and voice the student body opinion for two consecutive terms.

- Held position on Board of Trustees for three years as a student representative to present the Board with student opinion.

- Led meetings of the student body to facilitate voting for approval or denial of student organizations, budget recommendations, and other pieces applicable to campus and student life. 
- Designated as student assistant to the Dean of Admissions.

- Traveled for alumni events in Florida to raise money for the current Hanover College Campaign.

- Marketed Hanover College to prospective students by giving them campus tours and testimonies.

- Hosted prospective students overnight so they could experience a night in the life of a Hanover student.

- Engaged actively in admission activities and responded immediately whenever called upon.

\section{Other Extra-Curricular Activities}

- Senator to the Student Government Association on behalf of the Graduate Student Council

- Chair of the Advocacy and Involvement Committee on Graduate Student Council

- Graduate student representative on the Academic Policy Committee

- Sociology representative on Graduate Student Council

- Full voting member on Presidential Search Committee

- Vice President of Scholarship on Panhellenic Council

- Communications Chair on Student Senate

- Panhellenic Delegate for Chi Omega sorority

- Budget Coordinator for Love Is Needed by Kids

- Treasurer for Alpha Lambda Delta

- Student Representative on the Campus Community Culture Committee and the Standards Board

- Member of Math Club and Fellowship of Christian Athletes 


\section{Other Professional Development}

Summer Analyst: Perella Weinberg Partners

Denver, CO

- Interned for an award-winning $\$ 5.6$ billion multi-asset class

June-July 2014 investment firm named Outsourced $\mathrm{ClO}$ of the Year by Institutional Investor Magazine.

- Focused on manager due diligence and investment selection as a member of a hedge fund team.

- Completed specialized training in multiple asset classes including absolute return, global equities, global fixed income, private capital, and real assets.

- Conducted in-house and telephonic interviews with money managers across all asset classes.

- Assisted with asset allocation development through a macro view of markets.

\section{Men's Varsity Basketball Manager}

Hanover, IN

- Responsible for filming home games.

Fall 2012- May 2015

- Recruited prospective players for the program by giving tours and answering questions regarding the team and the college.

- Prepared supplies and ran clock for all practices.

\section{Waitress: The Thirty-Six Saloon}

Rockville, IN

- Trained as Assistant Manager from a financial

Summer 2012-Summer 2015 perspective.

- Provided an excellent dining experience to all customers while creating and developing interpersonal skills.

- Appropriated shifts for workers unable to make it to work and relied upon by manager to be on-call at all time 